\title{
International Benchmark on Numerical Simulations for 1D, Nonlinear Site Response (PRENOLIN): Verification Phase Based on Canonical Cases
}

by Julie Régnier, Luis-Fabian Bonilla, Pierre-Yves Bard, Etienne Bertrand, Fabrice Hollender, Hiroshi Kawase, Deborah Sicilia, Pedro Arduino, Angelo Amorosi, Domniki Asimaki, Daniela Boldini, Long Chen, Anna Chiaradonna, Florent DeMartin, Marco Ebrille, Ahmed Elgamal, Gaetano Falcone, Evelyne Foerster, Sebastiano Foti, Evangelia Garini, George Gazetas, Céline Gélis, Alborz Ghofrani, Amalia Giannakou, James R. Gingery, Nathalie Glinsky, Joseph Harmon, Youssef Hashash, Susumu Iai, Boris Jeremić, Steve Kramer, Stavroula Kontoe, Jozef Kristek, Giuseppe Lanzo, Annamaria di Lernia, Fernando Lopez-Caballero, Marianne Marot, Graeme McAllister, E. Diego Mercerat, Peter Moczo, Silvana Montoya-Noguera, Michael Musgrove, Alex Nieto-Ferro, Alessandro Pagliaroli, Federico Pisanò, Aneta Richterova, Suwal Sajana, Maria Paola Santisi d'Avila, Jian Shi, Francesco Silvestri, Mahdi Taiebat, Giuseppe Tropeano, Luca Verrucci, and Kohei Watanabe ${ }^{\dagger}$

\begin{abstract}
PREdiction of NOn-LINear soil behavior (PRENOLIN) is an international benchmark aiming to test multiple numerical simulation codes that are capable of predicting nonlinear seismic site response with various constitutive models. One of the objectives of this project is the assessment of the uncertainties associated with nonlinear simulation of $1 \mathrm{D}$ site effects. A first verification phase (i.e., comparison between numerical codes on simple idealistic cases) will be followed by a validation phase, comparing the predictions of such numerical estimations with actual strongmotion recordings obtained at well-known sites. The benchmark presently involves 21 teams and 23 different computational codes.

We present here the main results of the verification phase dealing with simple cases. Three different idealized soil profiles were tested over a wide range of shear strains with different input motions and different boundary conditions at the sediment/bedrock interface. A first iteration focusing on the elastic and viscoelastic cases was proved to be useful to ensure a common understanding and to identify numerical issues before pursuing the nonlinear modeling. Besides minor mistakes in the implementation of input parameters and output units, the initial discrepancies between the numerical results can be attributed to (1) different understanding of the expression "input motion" in different communities, and (2) different implementations of material damping and possible numerical energy dissipation. The second round of computations thus allowed a convergence of all teams to the Haskell-Thomson analytical solution in elastic and viscoelastic cases. For nonlinear computations, we investigate the epistemic uncertainties related only to wave propagation modeling using different nonlinear constitutive models. Such epistemic uncertainties are shown to increase with the strain level and to reach values around $0.2\left(\log _{10}\right.$ scale) for a peak ground acceleration of $5 \mathrm{~m} / \mathrm{s}^{2}$ at the base of the soil column, which may be reduced by almost $50 \%$ when the various constitutive models used the same shear strength and damping implementation.
\end{abstract}

\section{Introduction}

Including site effects in seismic-hazard assessments requires the consideration, at some stage, of nonlinear (NL) behavior of soils, which may greatly affect their dynamic response to strong motion and significantly modify their

*Also at EESA, Lawrence Berkeley National Laboratory, Berkeley, California 94720.

'The author's list involves first the seven organizers of the PRENOLIN project followed by the participants in alphabetic order. 
amplification behavior compared with weak motion (computed or measured). Even in areas of moderate seismicity, the hazard level at long to very long return periods (i.e., several thousands to tens of thousands years) may be large enough to generate significant strains in shallow soft soil layers, which in turn leads to a degradation of their mechanical properties such as hysteretic behavior with reduction of shear stiffness/ strength and increased energy dissipation (Seed, 1969; Vucetic and Dobry, 1991; Ishibashi and Zhang, 1993; Yu et al., 1993; Iai et al., 1995; Zeghal et al., 1995; Bonilla et al., 2005).

Such dependence of the dynamic soil response on the level of seismic loading, conventionally denoted as NL effects (Beresnev et al., 1995), involves rather complex mechanical processes, which may be grouped roughly in two main classes. The first is the degradation of the mechanical properties of the material, which is often characterized by a decrease in the shear stiffness and strength coupled with an increase in energy dissipation; whereas the second is related to pore pressure changes in water-saturated granular soils, linked with volumetric changes of the soil skeleton under shear stress, and may generate liquefaction in loose sandy soils. Our interest here focused on the first type of nonlinearity, without any consideration of pore water pressure generation or liquefaction.

The first type of NL effect (i.e., without liquefaction) was identified by geotechnical earthquake engineering studies following the 1967 Caracas earthquake and further corroborated by observations after the 1989 Loma Prieta (Chin and Aki, 1991) and the 1994 Northridge (Field et al., 1997) earthquakes. Moreover, this was later confirmed both by laboratory tests and recordings obtained on vertical arrays with two or more accelerometers at different depths within the same borehole. For instance, a statistical analysis of the numerous recordings of the Japanese KiK-net network (Régnier et al., 2013) concluded that, for peak ground acceleration (PGA) levels exceeding $0.75 \mathrm{~m} / \mathrm{s}^{2}$ (a rather moderate level) at an outcrop, there is a $40 \%$ chance of observing an NL soil response, leading to significant modifications with respect to the linear low-strain response. These changes generally imply a reduction of the response amplification of the signal's highfrequency (HF) content and often a slight-to-significant increase of its low-frequency (LF) content. Therefore, linear soil response estimates cannot be considered as being systematically on the safe side, and on the other hand, the HF reductions may significantly contribute to the safety margins. As a consequence, the accuracy, robustness, and reliability of NL site effects prediction directly impacts the estimation of seismic hazard and associated risks, especially at long return periods.

Although a consensus has undoubtedly been reached on the existence of NL effects, their quantification and modeling remain a challenge. Indeed, numerous techniques have been proposed for the assessment of the site effects in the linear domain using empirical and/or modeling approaches on a generic or site-specific basis. Conversely, empirical estimation of NL site effects is more limited, especially in moderate seismicity areas where the onsite instrumental approach can only be a long (to very long)-term investment. Aside from a generic approach based on existing recordings (Derras et al., 2012; Sandikkaya et al., 2013), the only presently possible way for site-specific estimates is thus numerical simulation. Obviously, such analysis must be preceded by a precise geotechnical and geophysical characterization of the underground structure, and the choice of a suitable NL constitutive model.

Given the complexity of NL behavior of soils, many constitutive models and codes have been developed for such simulations. When the deformation remains moderate (i.e., smaller than about $0.1 \%-0.3 \%$ ), the so-called equivalent linear model, which is a linear approach with an iterative adjustment of viscoelastic properties (shear modulus and damping) to the local strain level, is often used and accepted in practice. However, when the strain level exceeds these values (i.e., above $0.2 \%-0.5 \%$ ), which can occur in very soft soils and/or with very strong input motions, a complete NL modeling with an appropriate constitutive law fed by the correct soil parameters is required. These models fall into two categories: relatively simple constitutive laws with few parameters, that cannot reproduce a wide range of loading/ unloading paths; and more complex models with many parameters (sometimes exceeding 10), which can succeed in describing all possible behaviors, but with parameters that can be difficult to determine or calibrate.

The ability to accurately predict NL site responses has indeed already been the subject of two recent comparative tests. It was one of the targets of the pioneering blind tests initiated in the late 1980s/early 1990s, on two sites of Ashigara Valley (Japan) and Turkey Flat (California); however, those sites lacked strong-motion records until the 2004 Parkfield earthquake during which the Turkey Flat site experienced a $0.3 g$ motion. Because the soils were fairly stiff, the nonlinearity was not very strong. A new benchmarking of 1D NL codes was thus carried out in the last decade, based on the Turkey Flat site and a few other sites with vertical array data (La Cienega, California; the KGWH02 KiK-net site in Japan, and Lotung in Taiwan). Its main findings, reported by Kwok et al. (2008) and Stewart and Kwok (2009), emphasized the key importance of the way these codes are used and of the required in situ measurements. Significant differences between records and predictions have been postulated as being due to an incorrect velocity profile (although it was derived from redundant borehole measurements), a non-1D soil geometry (nonhorizontal layers), and imperfections/deficiencies in the constitutive models, which were unable to represent the actual curves for stiffness reduction and damping increase. Another test was undertaken on the Euroseis European test site (Mygdonian graben near Thessaloniki, Greece) as part of the Cashima/E2VP (EUROSEISTEST Verification and Validation Project) project, which included two separate exercises on 2D NL numerical simulation codes and 3D linear simulation codes. The 2D NL benchmark proved inconclusive, because major differences were found between the few considered codes, with multiple possible causes, that is, 2D numerical scheme, damping implementation, and NL constitutive laws (see Foerster et al., 2015). Given the fact that the 


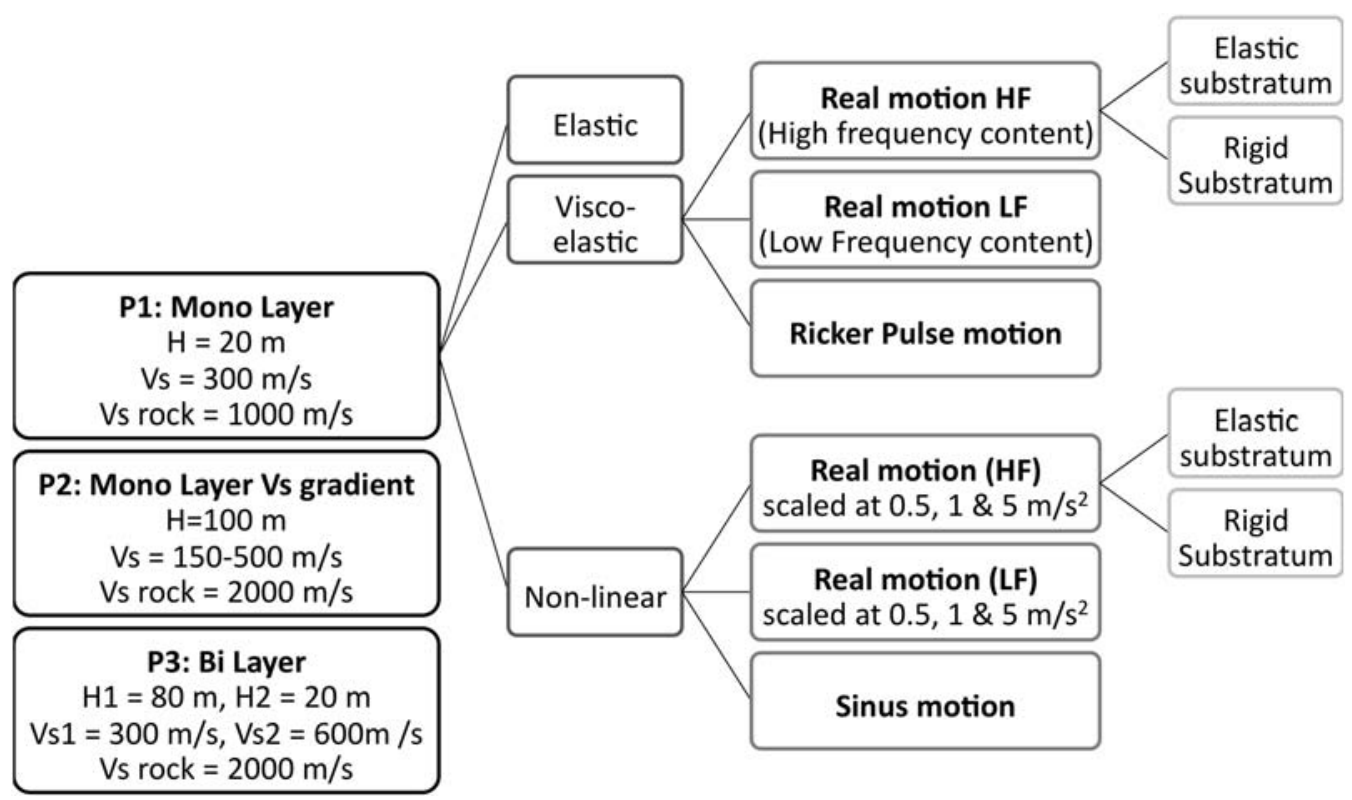

Figure 1. The three simple idealized profile cases studied here (P1-P3), for the elastic and nonelastic domains, and for a rigid and elastic soil-bedrock base, using a Ricker pulse and three accelerations of different peak ground acceleration (PGA) and frequency contents.

codes used for these tests are routinely used in engineering practice for predictions of NL site responses, especially for moderate seismicity countries lacking strong-motion recordings, there is a clear need to conduct further tests in better controlled conditions, in particular with in situ and laboratory measurements for an optimal tuning of the NL parameters used in each code.

For this reason, the PREdiction of NOn-LINear soil behavior (PRENOLIN) project considers only 1D soil columns to test the NL codes in the simplest possible, though realistic, geometries. It is organized in two phases: (1) a verification phase aiming at a cross-code comparison on very simple (and idealistic) 1D soil columns with prescribed linear and NL parameters; and (2) a validation phase for comparison between numerical predictions and actual observations, for sites as close as possible to a 1D geometry (horizontal stratification), without liquefaction evidence and with already available sets of downhole and surface recordings for weak to very strong motions and later complemented by careful in situ and laboratory measurements designed as close as possible to the participant's requirements. The sites were selected within the Japanese KiK-net and Port and Airport Research Institute (PARI) accelerometric networks.

The purpose of this article is to present and discuss the results of the verification phase, with a special focus on the epistemic uncertainties associated with the constitutive laws and numerical schemes of the simulation codes. The first section describes the three idealized soil columns and the requested computations, considering different boundary conditions (rigid/elastic base, associated respectively with/ within outcropping reference motion). The next section lists the numerous teams that volunteered to participate in this exercise and the main characteristics of their codes. The sim- ulation results are then presented and compared, first in the linear case (with and without attenuation), and then in the NL case for various input signals and levels, with a discussion in each case on the amount and origins of uncertainty.

\section{The Canonical Cases}

The verification phase of this project aims at establishing the similarity between the computed wave motions at the surface of a soil column affected by amplification using different numerical codes, quantifying the amount of code-to-code differences and, as much as possible, understanding them. The computed responses were compared with analytical solutions when available. Figure 1 summarizes the calculations performed during the verification phase, for the linear (elastic and viscoelastic) and NL cases. In the elastic and viscoelastic cases, for which analytical results are available and provided that all participants/users share a common understanding of the physical soil parameters to be used, no differences (or minor) in the results are expected. These first calculations are needed in order to ensure a proper predictability of the induced deformation (shear strain) for all soil and seismic-wavefield properties. On the other hand, for NL cases, discrepancies between the different computations are expected: the goal is to identify their origins in relation to the constitutive models and/or the numerical schemes (or other possible issues), to quantify the associated epistemic uncertainty, and to reduce it to its minimum level as much as possible.

The experiment was designed around three 1D canonical cases, chosen to represent simple and idealistic soil conditions overlying stiff bedrock substrata:

1. Profile 1 (P1) is a shallow ( $20 \mathrm{~m}$ thick) homogeneous soil layer presenting a significant velocity impedance ratio at 


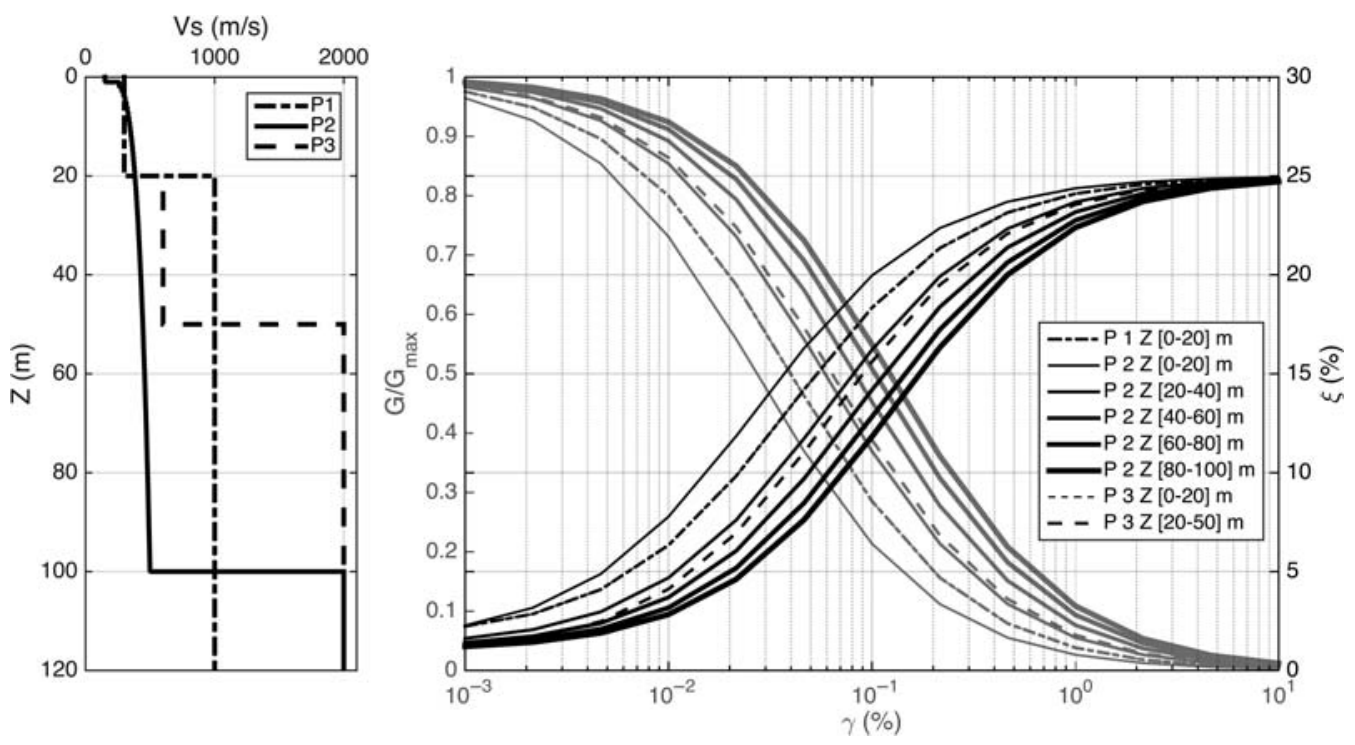

Figure 2. $V_{S}$ profiles, $G / G_{\max }$, and damping curves for the three idealized profiles.

rock, with amplification in the intermediate frequency range $(2-10 \mathrm{~Hz})$.

2. Profile 2 (P2) is a thick $(100 \mathrm{~m})$ soil layer with $S$-wave velocity gradually increasing with depth, overlying a very stiff bedrock, with a low fundamental frequency (below $1 \mathrm{~Hz})$.

3. Profile 3 (P3) consists of two homogeneous layers with moderate velocity contrasts, overlying a very stiff bedrock, with expected amplification effects in the intermediate frequency range $(2-10 \mathrm{~Hz})$. The goal is to investigate nonlinearity effects within both layers, because significant strains can develop at or near each interface.

Various reference motions are considered for each profile, from very simple signals intended to capture the basic physics of NL behavior (pulse-like and cyclic, quasimonochromatic signals with increasing amplitude), to realistic accelerograms. For the latter, two strong motions were selected with very different spectral content (HF and LF contents), and scaled to three PGA levels, in order to generate a wide range of shear-strain levels in the soil column.

These reference motions were applied at the bedrock level, with two boundary conditions representative of the actual case studies: in one case, the reference motion was considered to mimic the outcropping motion at the surface of the underlying bedrock (elastic condition), whereas in the other it was considered to mimic the within motion recorded by a virtual sensor at the sediment-bedrock interface (rigid condition).

\section{Soil Properties}

The properties describing the (1D) linear and NL soil behavior for each profile include elastic, viscoelastic, and NL soil properties. They are displayed in Figures 1 and 2, and summarized in Table 1.
The basic characteristics of soil profiles (i.e., thickness, density, and seismic-wave velocities) were chosen in order to be representative of typical soil profiles. Values of $P$-wave velocity $\left(V_{P}\right)$ are derived from the profiles of $S$-wave velocity $\left(V_{S}\right)$ shown in Figure 2, using assumed values of Poisson ratio (0.4 for soil and 0.3 for bedrock). Profiles P1 and P3 exhibit constant seismic velocities in each layer, whereas P2 includes a velocity gradient with a regular increase from $V_{S}=150 \mathrm{~m} / \mathrm{s}$ at the surface to $V_{S}=500 \mathrm{~m} / \mathrm{s}$ at the soil-bedrock interface, according to:

$$
V_{S}(z)=V_{S 1}+\left(V_{S 2}-V_{S 1}\right)\left(\frac{z-Z_{1}}{Z_{2}-Z_{1}}\right)^{\alpha}
$$

in which $V_{S 1}=150 \mathrm{~m} / \mathrm{s}$ and $V_{S 2}=500 \mathrm{~m} / \mathrm{s}$ are the shearwave velocities at depths $Z_{1}=0 \mathrm{~m}$ and $Z_{2}=100 \mathrm{~m}$, respectively, and $V_{S}(z)$ is the shear-wave velocity at depth $z ; \alpha$ is taken equal to 0.25 .

Viscoelastic Properties. We only consider intrinsic material damping (Biot, 1956; Johnston et al., 1979; Leurer, 1997) without any additional component from scattering. Intrinsic attenuation can be quantified by the quality factor $Q$ (more commonly used in seismology), or the damping ratio $\xi$ (used in engineering seismology). Here, $Q$ and $\xi$ are the quality factor and the damping ratio of the $S$ waves. They are linked by the formula $Q=1 /(2 \xi)$, and can be determined by the loss of energy over one wavelength. Pure elastic materials totally restore the seismic energy after deformation, and should therefore have infinite $Q$ values; as the numerical codes used here require a finite value as input, the elastic case was computed with very high values of $Q$ (very low $\xi$ ) for both soil and bedrock $(Q=5000)$. For viscoelastic and NL (soft) materials, the energy dissipation at low strain was constrained to vary according to $V_{S}$, through the classical—never appropriately 
Table 1

Soil Properties for All Three Simple Profile Cases Studied Here (P1-3), for the Elastic and Nonelastic Domains

\begin{tabular}{|c|c|c|c|c|c|c|c|c|c|c|}
\hline \multirow[b]{2}{*}{ Profile } & \multicolumn{9}{|c|}{ Linear } & \multirow[b]{2}{*}{$\mathrm{NL}^{*}$} \\
\hline & $Z(\mathrm{~m})$ & $V_{S}(\mathrm{~m} / \mathrm{s})$ & $V_{P}(\mathrm{~m} / \mathrm{s})$ & $\rho\left(\mathrm{kg} / \mathrm{m}^{3}\right)$ & $Q$ Elastic & $\begin{array}{l}\xi_{\min } \\
\text { Elastic }\end{array}$ & $\begin{array}{c}Q \\
\text { Viscoelastic }\end{array}$ & $\begin{array}{c}\xi_{\min } \\
\text { Viscoelastic }\end{array}$ & $\begin{array}{c}f_{0} \text { Linear } \\
\text { Elastic }(\mathrm{Hz})\end{array}$ & \\
\hline \multirow[t]{2}{*}{$\mathrm{P} 1$} & $0-20$ & 300 & 700 & 2000 & 5000 & $10^{-4}$ & 30 & 0.0166 & 3.75 & $\mathrm{~N}^{\circ} 1-\mathrm{P} 1$ \\
\hline & - & 1000 & 1900 & 2500 & & & 200 & 0.0025 & & - \\
\hline \multirow[t]{6}{*}{$\mathrm{P} 2$ mono-layer $+V_{\text {gradient }}$} & $0-20$ & $150-500$ & $360-1220$ & 2000 & & & 34 & 0.01547 & 1.16 & $\mathrm{~N}^{\circ} 1-\mathrm{P} 2$ \\
\hline & $20-40$ & & & & & & 40 & 0.0250 & & $\mathrm{~N}^{\circ} 2-\mathrm{P} 2$ \\
\hline & $40-60$ & & & & & & 44 & 0.0113 & & $\mathrm{~N}^{\circ} 3-\mathrm{P} 2$ \\
\hline & $60-80$ & & & & & & 47 & 0.0106 & & $\mathrm{~N}^{\circ} 4-\mathrm{P} 2$ \\
\hline & $80-100$ & & & & & & 49 & 0.0102 & & $\mathrm{~N}^{\circ} 5-\mathrm{P} 2$ \\
\hline & - & 2000 & 3700 & 2500 & & & 200 & 0.0025 & & - \\
\hline \multirow[t]{3}{*}{ P3 bi-layer } & $0-20$ & 300 & 700 & 2000 & & & 30 & 0.0166 & 1.48 & $\mathrm{~N}^{\circ} 1-\mathrm{P} 3$ \\
\hline & $20-100$ & 600 & 1500 & 2000 & & & 60 & 0.0083 & & $\mathrm{~N}^{\circ} 2-\mathrm{P} 3$ \\
\hline & - & 2000 & 3700 & 2500 & & & 200 & 0.0025 & & - \\
\hline
\end{tabular}

$Z$, depth of the soil layer; $V_{S}$, shear-wave velocity; $V_{P}$, compressional wave velocity; $\rho$, density; $Q$, quality factor; $\xi_{\min }$, elastic damping; $f_{0}$, fundamental resonance frequency of the soil.

*Describe the $G / G_{\max }$ and damping curves used for each soil layer; NL, nonlinear.

justified by measurements-relationship $Q=V_{S} / 10$, or equivalently $\xi=5 / V_{S}\left(V_{S}\right.$ in $\mathrm{m} / \mathrm{s}$; Olsen et al., 2003).

Non-linear Soil Properties. The NL properties of each layer were characterized using classical $G / G_{\max }(\gamma)$ and $\xi(\gamma)$ curves, relating the decay of shear modulus $(G)$ normalized by the elastic shear modulus $\left(G_{\max }\right)$ and increase of damping $\xi$ with the shear strain $\gamma$. Normally, we would expect to have available measurements from laboratory or field experiments to derive the necessary parameters for a given rheology model. However, in order to verify the ability of different models to take into account the same shear modulus reduction and damping ratio data and to simplify the canonical soil description, and also to start with an analysis of only the code-to-code variability, $G / G_{\max }(\gamma)$ and $\xi(\gamma)$ curves were constructed following a simple hyperbolic model based on the following equations:

$$
\begin{gathered}
K_{0}=(1-\sin (\phi)) \times \mathrm{OCR}^{\sin (\phi)} \\
\sigma_{m}^{\prime}=\sigma_{v}^{\prime}\left(1+2 K_{0}\right) / 3 \\
\tau_{\max }=\sigma_{m}^{\prime} \sin (\phi) \\
\gamma_{\mathrm{ref}}=\tau_{\max } / G_{\max } \\
G / G_{\max }=1 /\left(1+\gamma / \gamma_{\mathrm{ref}}\right) \\
\xi=\xi_{\min }+\left(\xi_{\max }-\xi_{\min }\right)\left(\gamma / \gamma_{\mathrm{ref}}\right) /\left(1+\gamma / \gamma_{\mathrm{ref}}\right)
\end{gathered}
$$

in which the control parameters are the friction angle $\phi=30^{\circ}$, the overconsolidation ratio $\mathrm{OCR}=1$, and the gravitational acceleration $g=9.81 \mathrm{~m} / \mathrm{s}^{2}$. Only cohesionless material was considered here, so that the shear strength $\tau_{\max }$ is computed using the vertical stress and the friction angle. Both $\sigma_{m}^{\prime}$ and $\sigma_{v}^{\prime}$ are the effective mean and vertical stresses; $\gamma$ is the shear strain. The reference shear strain $\gamma_{\text {ref }}$ corresponds to the strain for which $G=0.5 G_{\max }$ (in the hyperbolic model as described above by equation 5), $K_{0}$ is the coefficient of earth pressure at rest, and $\xi_{\min }$ and $\xi_{\max }$ are the minimum damping values at very low strain (intrinsic material damping considered above for the viscoelastic behavior) and the maximum at very high strain, respectively.

Only one $G / G_{\max }(\gamma)$ and $\xi(\gamma)$ curves were provided for $\mathrm{P} 1$, five for $\mathrm{P} 2$ (increasing for each 20-m depth interval), and two for P3 (one for each homogeneous layer). We assume a constant strength per soil layer for all soil models. They are illustrated in Figure 2. For P1 and P2, they are fitting a hyperbolic curve defined by the low-strain shear modulus $G_{\max }=$ $\rho V_{S}^{2}$ and the shear strength $\tau_{\max }$ at the center of each layer or sublayer. For P3, the $G / G_{\max }(\gamma)$ and $\xi(\gamma)$ chosen models were very similar to one another using the previous hyperbolic model. For P3, the set of the Darendeli (2001) models was used and adjusted to a simple hyperbolic model as for P1 and P2; as Darendeli's models are defined only up to a maximum shear strain of $1 \%$, the P3 curves were defined by multiplying the shear strength $\tau$ by factors 1.1 and 2 at depths of 10 and $35 \mathrm{~m}$, respectively, and the final curves were then computed based on the hyperbolic models associated with these values.

Some numerical codes include sophisticated constitutive models for NL soil behavior, which require very specific additional parameters and should be consistent with the $G / G_{\max }(\gamma)$ and $\xi(\gamma)$ curves supplied for the other codes. The definition of these additional parameters was done individually by each team, with the following simple assumptions: the soil is cohesionless (i.e., $c^{\prime}=0$ and plasticity index PI $=0$ ), the soil particle size distribution is defined 

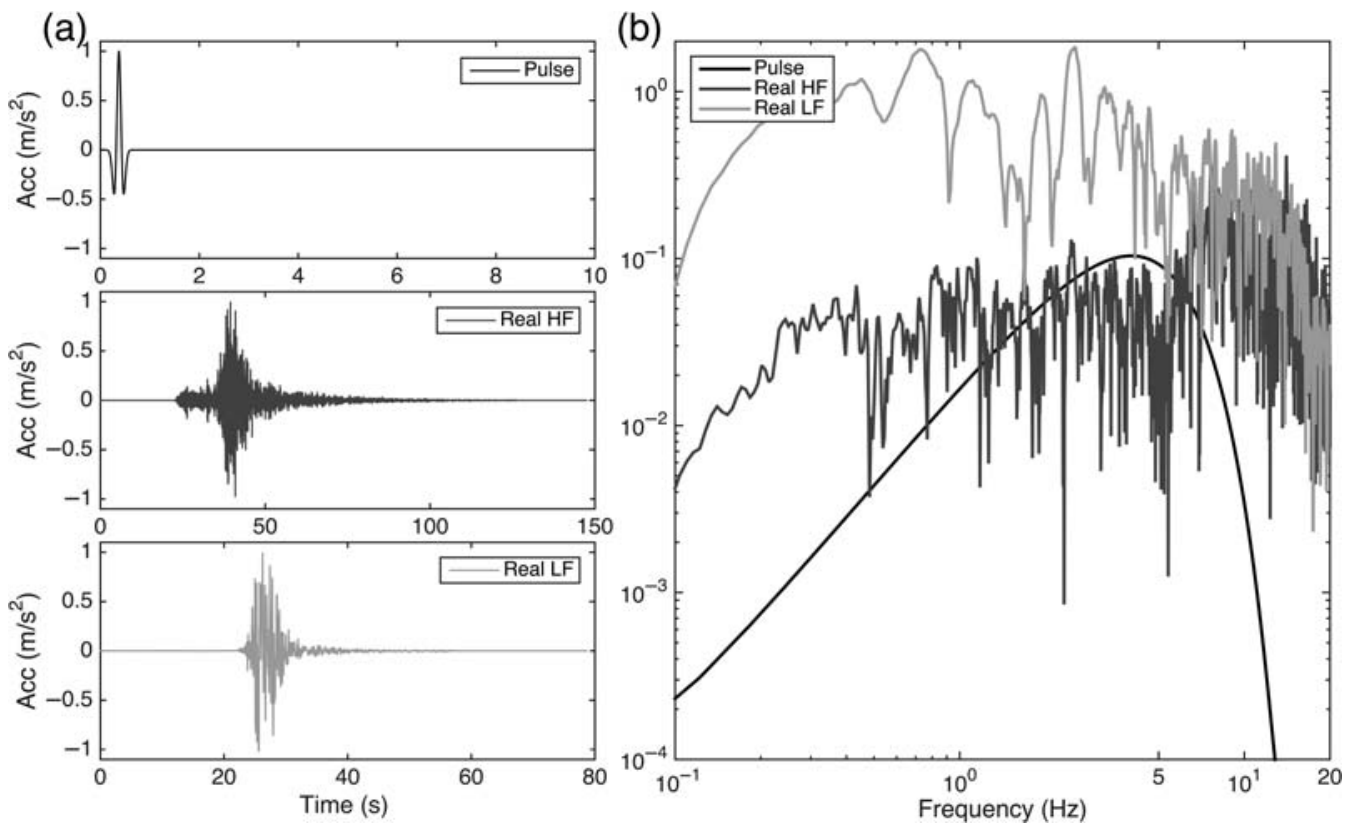

Figure 3. Normalized acceleration of the reference motions used for the verification phase (pulse, real motions: high-frequency [HF] motion and low-frequency [LF] motion) of this PREdiction of NOn-LINear soil behavior (PRENOLIN) project (a) with the associated Fourier spectrum (b).

with $D_{10}=0.2 \mathrm{~mm}$ and $D_{50}=0.35 \mathrm{~mm}$, and a uniformity coefficient $D_{60} / D_{10}=1.8$.

\section{Reference Rock Motion}

In the first phase of the project, each participant was provided (1) a simple Ricker pulse input motion derived analytically, and (2) two real acceleration time-histories scaled to three different PGA levels $\left(0.5,1\right.$, and $\left.5 \mathrm{~m} / \mathrm{s}^{2}\right)$ to observe the evolution from linear to NL soil behavior. The two accelerograms were selected to be representative of very different frequency contents, in order to analyze its influence in the NL computations. Each accelerogram was preprocessed in the same way as explained further below. The Fourier transforms of the three normalized input motions are illustrated in Figure 3.

The Pulse-Like Input Motion. The Ricker pulse input motion corresponds to acceleration, velocity, and displacement time histories defined by equations (8)-(10). A central frequency of $4 \mathrm{~Hz}$ was chosen to produce sufficient energy at the fundamental frequency of each of the three profiles, while having a broadband energy in the main bandwidth of earthquake geotechnical engineering (i.e., $1-10 \mathrm{~Hz}$ ):

$$
\begin{gathered}
a(t)=\left[1-2\left(\pi t f_{c}\right)^{2}\right] \exp \left(-\left(\pi t f_{c}\right)^{2}\right) \\
v(t)=t \exp \left(-\left(\pi t f_{c}\right)^{2}\right) \\
d(t)=\frac{1}{-2\left(\pi f_{c}\right)^{2}} \exp \left(-\left(\pi t f_{c}\right)^{2}\right),
\end{gathered}
$$

in which $f_{c}$ is the central frequency and $a(t), v(t)$, and $d(t)$ are the acceleration, velocity, and displacement time histories, respectively. The acceleration time histories and the normalized Fourier transform spectra for the three input motions are illustrated in Figure 3.

Real Reference Input Motions. To investigate the effect of frequency content on the computation of NL soil behavior, we used two real input motions with different frequency contents recorded at rock outcrop sites. One has a predominant frequency of $11.4 \mathrm{~Hz}$, the second has $4.8 \mathrm{~Hz}$ : they are labeled hereafter $\mathrm{HF}$ and $\mathrm{LF}$, respectively. The metadata of these two recordings are described in Table 2, and their acceleration, velocity, and displacement time histories are illustrated in Figure 3. We can observe that the spectral shapes are quite different, the main energy of the signal for the LF motion lies between 0.5 and $10 \mathrm{~Hz}$, and HF motion lies between 5 and $20 \mathrm{~Hz}$. The duration of the HF event is about $80 \mathrm{~s}$, whereas it is shorter for the LF motion around 15 s. In this work, we considered only the horizontal east-west (EW) component of each recording.

The velocity and displacement time histories of these two recordings were calculated from the original raw acceleration data, following this procedure: (1) removal of the mean, (2) zero padding of the signal by applying Boore's approach (Boore and Bommer, 2005) over a specific time duration corresponding to $20 \mathrm{~s}$ before the first, and after the last, zero crossing of the original acceleration time series, (3) high-pass filtering of the signal, and (4) integrating twice to obtain consistent velocity and displacement time histories. 
Table 2

Seismic Metadata of the Two Real Input Motions Used in the Verification Phase of the PREdiction of NOn-LINear Soil Behavior (PRENOLIN) Project

\begin{tabular}{|c|c|c|c|c|c|c|c|c|}
\hline $\begin{array}{c}\text { Event Frequency } \\
\text { Content }\end{array}$ & Event ID & $M_{\mathrm{w}}$ & $Z(\mathrm{~km})$ & $\begin{array}{c}\text { Epicentral } \\
\text { Distance }(\mathrm{km})\end{array}$ & Station ID & $\begin{array}{l}\text { Station } \\
\text { Geology }\end{array}$ & $\begin{array}{l}\text { Seismo. } \\
\text { Comp. }\end{array}$ & $V_{S 30}(\mathrm{~m} / \mathrm{s})$ \\
\hline $\mathrm{HF}$ & IWTH-170112022202 & 6.4 & 122 & 39 & IWTH17 (KiK-net, Japan) & Rock & EW & $>1200$ \\
\hline LF & 06756. 20000617 & 6.6 & 15 & 5 & Flagbjarnarholt (Iceland) & A & H1 & Unknown \\
\hline
\end{tabular}

$M_{\mathrm{w}}$, moment magnitude; $Z$, depth of epicenter; $V_{S 30}$, mean harmonic $S$-wave velocity over the first $30 \mathrm{~m}$ depth; Seismo. Comp., the component of motion of the seismogram.

\section{Participants and Tested Numerical Codes}

We compared 23 different numerical codes used by 21 participating teams, as listed in Table 3. As some teams use several codes, each computational case/team is annotated by a letter and a number. Two or more teams used the same code, including DEEPSOIL v.5.1 (four teams for the verification and five for the validation), Fast Lagrangian Analysis of Continua (FLAC) (two teams), and OpenSees (three teams). Others used the same constitutive model, notably the Iai et al. (1990) model (two teams), Iwan's model (Iwan, 1967; Ishihara, 1996) (four teams), and the Hujeux model (Aubry et al., 1982) (two teams). The participant teams were composed of people having different backgrounds and expertises, which can be relevant for analyzing the site response variability. First, two disciplines are represented in this benchmark, seismology and geotechnical earthquake engineering, and second, the participants are either developers or users.

We identified three different non-exclusive code groups, according to three main characteristics: (1) the type of numerical scheme, (2) the way to implement the attenuation, either in the low-strain range or in the high-strain range, and (3) the type of NL constitutive models. Each of these three groups is detailed in the following sections.

\section{The Numerical Scheme}

The 20 codes that solve the problem in time domain are split in two main categories: two types of spatial approximations are considered.

1. The finite-element method is by far the most common, used by 18 teams and implemented in three different ways:

- standard method, used by 12 teams: B-0, D-0, H-0, L-1, $\mathrm{M}-1, \mathrm{~N}-0, \mathrm{R}-0, \mathrm{~S}-0, \mathrm{~T}-0, \mathrm{U}-0, \mathrm{~W}-0$, and Z-1

- spectral method, used by 1 team: Q-0

- discontinuous Galerkin method, used by 1 team: Y-0.

2. The finite-difference method is used by 10 teams: A-0, C-0, E-0, F-0, G-0, J-0, K-0, L-2, M-0, and M-2.

The last remaining teams $(\mathrm{J}-1, \mathrm{~T}-1$, and Z-0) consider the problem in the frequency domain and use an equivalent linear method involving linear viscoelastic material with several iterations to tune the viscoelastic properties in each layer to the shear strain and modulus reduction and damping curves (Schnabel et al., 1972).

\section{Implementation of Attenuation}

Low-Strain Attenuation. At low-strain levels (less than $10^{-4} \%-10^{-2} \%$ ), elasto-plastic constitutive models and most of the NL models have damping values close to zero, which is physically unrealistic, because all soil strata exhibit damping in the stress-strain plane even for weak deformations, indicating dissipation of energy.

In the frequency domain, implementation of a prescribed attenuation factor is relatively straightforward. In theory, fulfillment of the causality principle leads to a (slight) frequency dependence of the shear-wave velocity, which should be specified (together with the damping value) at a specific frequency $f_{0}$ (Aki and Richards, 2002). However, this is not implemented in all codes: some consider a truly frequency-independent attenuation with a defined reference frequency for the velocity, while others dropped the causality principle and have frequency independent velocities.

In the time domain, attenuation can be approximated by implementation of a set of relaxation functions using rheological models such as the generalized Maxwell model (Day and Minster, 1984; Blanch et al., 1995; Day and Bradley, 2001; Graves and Day, 2003) or modeled by a Rayleigh damping formulation. Both methods present pros and cons. The usage of rheological models to approximate attenuation is physical; however, it adds memory constraints to the computations. The greater the number of relaxation functions used, the better the attenuation factor will be approximated, although one should not use too many (see e.g., Peyrusse et al., 2014). On the contrary, the Rayleigh damping method is much easier to be implemented numerically; nevertheless, the parameters are not easily determined, and automatically involve a significant frequency dependence of $Q$. For low attenuation (below a damping ratio of 20\%), it has been shown that Rayleigh damping and the generalized Maxwell model become equivalent (Semblat, 1997).

For the entire set of codes tested here, four kinds of attenuation implementations were used.

1. Frequency-independent attenuation: Some models considered frequency-independent attenuation instead of the use of the frequency-dependent Rayleigh damping/ 
Table 3

Participants to the PRENOLIN Project Verification Phase

\begin{tabular}{|c|c|c|c|c|c|}
\hline Team Name & Affiliation & & & Code Name & Code Reference \\
\hline D. Asimaki and J. Shi & Caltech, Pasadena, California & A & 0 & SeismoSoil & $\begin{array}{l}\text { Matasovic and Vucetic (1993), Li and } \\
\text { Assimaki (2010), and J. Shi and D. } \\
\text { Asimaki (unpublished manuscript, } \\
\text { 2016; see Data and Resources) }\end{array}$ \\
\hline S. Iai & $\begin{array}{l}\text { DPRI, Kyoto University, Kyoto, } \\
\text { Japan }\end{array}$ & $\mathrm{B}$ & 0 & FLIP & Iai et al. (1990) \\
\hline S. Kramer & $\begin{array}{l}\text { University of Washington, Seattle, } \\
\text { Washington }\end{array}$ & $\mathrm{C}$ & 0 & PSNL & In development \\
\hline E. Foerster & CEA, France & $\mathrm{D}$ & 0 & CyberQuake & Modaressi and Foerster (2000) \\
\hline C. Gelis & IRSN, France & $\mathrm{E}$ & 0 & NOAH-2D & Iai et al. (1990) \\
\hline A. Giannakou & Fugro, Nanterre Cedex, France & $\mathrm{F}$ & 0 & DEEPSOIL 5.1 & Hashash et al. (2012) \\
\hline $\begin{array}{l}\text { G. Gazetas, E. Garini, and N. } \\
\text { Gerolymos }\end{array}$ & NTUA, Greece & G & 0 & NL-DYAS & Gerolymos and Gazetas $(2006,2005)$ \\
\hline J. Gingery and A. Elgamal & UCSD, La Jolla, California & $\mathrm{H}$ & 0 & $\begin{array}{l}\text { OpenSees-UCSD } \\
\text {-SOIL-MODEL }\end{array}$ & See Data and Resources \\
\hline \multirow[t]{2}{*}{ Y. Hashash and J. Harmon } & $\begin{array}{l}\text { University of Illinois, Champaign, } \\
\text { Illinois }\end{array}$ & $\mathrm{J}$ & 0 & DEEPSOIL-NL 5.1 & Hashash et al. (2012) \\
\hline & & $\mathrm{J}$ & 1 & DEEPSOIL-EL 5.1 & Hashash et al. (2012) \\
\hline $\begin{array}{l}\text { P. Moczo, J. Kristek, and A. } \\
\text { Richterova }\end{array}$ & $\begin{array}{l}\text { CUB, Comenius University, } \\
\text { Bratislava, Slovakia }\end{array}$ & $\mathrm{K}$ & 0 & 1DFD-NL-IM & \\
\hline \multirow[t]{2}{*}{ S. Foti and S. Kontoe } & $\begin{array}{l}\text { Politecnico di Torino, Torino, Italy } \\
\text { and Imperial College, United } \\
\text { Kingdom }\end{array}$ & $\mathrm{L}$ & 1 & ICFEP & $\begin{array}{l}\text { Potts and Zdravkovic (1999), Kontoe } \\
\text { (2006), Taborda et al. (2010) }\end{array}$ \\
\hline & & $\mathrm{L}$ & 2 & DEEPSOIL-NL 5.1 & Hashash et al. (2012) \\
\hline \multirow[t]{3}{*}{$\begin{array}{l}\text { G. Lanzo, S. Suwal, A. } \\
\text { Pagliaroli, and L. Verrucci }\end{array}$} & $\begin{array}{l}\text { University of Rome La Sapienza and } \\
\text { University of Chieti-Pescara, Italy }\end{array}$ & M & 0 & FLAC_7,00 & ITASCA (2011) \\
\hline & & M & 1 & DMOD2000 & Matasović and Ordóñez (2010) \\
\hline & & M & 2 & DEEPSOIL 5.1 & Hashash et al. (2012) \\
\hline $\begin{array}{l}\text { F. Lopez-Caballero and S. } \\
\text { Montoya-Noguera }\end{array}$ & $\begin{array}{l}\text { CentraleSupélec, Paris-Saclay } \\
\text { University, Châtenay-Malabry, } \\
\text { France }\end{array}$ & $\mathrm{N}$ & 0 & GEFDyn & Aubry and Modaressi (1996) \\
\hline F. De-Martin & BRGM, France & Q & 0 & EPISPEC1D & $\begin{array}{l}\text { Iai } \text { et al. (1990) See Data and } \\
\text { Resources }\end{array}$ \\
\hline $\begin{array}{l}\text { B. Jeremić, F. Pisanò, and K. } \\
\text { Watanabe }\end{array}$ & $\begin{array}{l}\text { UCD, LBLN, TU Delft \& Shimizu } \\
\text { Corp }\end{array}$ & $\mathrm{R}$ & 0 & Real ESSI Simulator & See Data and Resources \\
\hline A. Nieto-Ferro & EDF, Paris, France & $\mathrm{S}$ & 0 & Code_aster & See Data and Resources \\
\hline \multirow[t]{2}{*}{$\begin{array}{l}\text { A. Chiaradonna, F. Silvestri, } \\
\text { and G. Tropeano }\end{array}$} & $\begin{array}{l}\text { UNICA and University of Naples, } \\
\text { Naples, Italy }\end{array}$ & $\mathrm{T}$ & 0 & SCOSSA 1.2 & Tropeano et al. (2016) \\
\hline & & $\mathrm{T}$ & 1 & STRATA & \\
\hline M. P. Santisi d'Avila & $\begin{array}{l}\text { University of Nice Sophia Antipolis, } \\
\text { Nice, France }\end{array}$ & $\mathrm{U}$ & 0 & SWAP_3C & $\begin{array}{l}\text { Santisi d'Avila et al. (2012, 2013), } \\
\text { Santisi d'Avila and Semblat (2014) }\end{array}$ \\
\hline D. Mercerat and N. Glinsky & CEREMA, France & $\mathrm{Y}$ & 0 & DGNL & Mercerat and Glinsky (2015) \\
\hline \multirow[t]{2}{*}{$\begin{array}{l}\text { D. Boldini, A. Amorosi, A. di } \\
\text { Lernia, and G. Falcone }\end{array}$} & $\begin{array}{l}\text { Unversity of Bologna, Sapienza } \\
\text { University of Rome, and } \\
\text { Politecnico di Bari, Italy }\end{array}$ & $\mathrm{Z}$ & 0 & EERA & Bardet et al. (2000) \\
\hline & & $\mathrm{Z}$ & 1 & PLAXIS & Benz (2006), Benz et al. (2009) \\
\hline M. Taiebat and P. Arduino & $\begin{array}{l}\text { UBC, British Columbia, Canada and } \\
\text { University of Washington, Seattle, } \\
\text { Washington }\end{array}$ & $\mathrm{W}$ & 0 & OpenSees & See Data and Resources \\
\hline
\end{tabular}

DPRI, Disaster Prevention Research Institute; CEA, Commissariat à l'Energie Atomique; IRSN, Institut de Radioprotection et de Sûreté Nucléaire; NTUA, National Technical University of Athens; UCSD, University of California, San Diego; ECP, Eclode Centrale Paris-Supelec; BRGM, Bureau De Recherches Géologiques et Minières; UCD, University of California, Davis; LBLN, Lawrence Berkeley National Laboratory; EDF, Electricité de France; UNICA, University of Calgari; CEREMA, centre d'études et d'expertise sur les risques, l'environnement, la mobilité et l'aménagement; UBC, University of British Columbia.

attenuation in the time-domain analysis. Models A-0, E-0, K-0, Q-0, T-1, and Z-0 use series of Maxwell/ Zener elements (Day and Minster, 1984; Blanch et al., 1995; Day and Bradley, 2001; Graves and Day, 2003), which imply an almost constant attenuation over a specific broad enough frequency range. Models F-0, J-0, and M-2 used the frequency-independent attenuation as proposed in Phillips and Hashash (2009). 
2. Frequency-dependent attenuation, such as Rayleigh damping (simplified or full), was used by 12 teams: B-0, G-0, H-0, L-1, M-0, M-1, R-0, S-0, T-0, W-0, Y-0, and Z-1.

3. Low-strain frequency-independent hysteretic damping was used by four teams: C-0, N-0, D-0, and R-0.

4. Numerical damping (ND): Three teams (U-0, N-O and D-0) use a variant of the Newmark integration scheme to simulate attenuation effects with purely ND tools, whereas another team (L-1) used it to filter out numerical noise.

High-Strain Attenuation. High-strain attenuation can be computed directly from the hysteretic behavior of the soil subjected to strong ground motion (loading/unloading cycles). However, it was demonstrated that it is difficult to reproduce simultaneously the specified decrease of $G / G_{\max }$ with increasing shear strain and damping. For this reason, a few teams (A-0, B-0, and E-0) chose to use a damping control (which implies a modification of the Masing rules, and is thus labeled as "no-Masing rules") based on mapping that converts a hysteresis loop in such a way that it will satisfy the hysteretic damping at the current strain level (Iai et al., 1992). Other teams (F-0, J-0, M-2, and T-0) used the method proposed in Phillips and Hashash (2009), which modifies the unload and reload paths of the extended Masing rules.

\section{NL Constitutive Models}

In geotechnical earthquake engineering, NL soil behavior is a well-established concept. In laboratory experiments, such as cyclic triaxial tests, the NL soil behavior is expressed by hysteresis loops in axial stress-strain plots, which can be linked to shear stress-strain plots. The soil response under cyclic loading (representing seismic loading) depends on cyclic loading (e.g., time history and peak amplitude) and soil (e.g., strength and relative density) properties.

In NL models, the true hysteresis soil behavior is simulated by the use of constitutive models that mimic the experimental hysteresis curves, or the shear modulus decay $\left[G / G_{\max }(\gamma)\right]$ and attenuation $[\xi(\gamma)]$ curves.

According to information gathered from each participant, the codes tested here are implemented with various NL models, including:

- Iai's model (Iai and Ozutsumi, 2005; Iai et al., 2011): B-0, E-0;

- modified Kondner and Zelasko hyperbolic model (Matasovic and Vucetic, 1993): A-0;

- Cundall (2006) model: M-0;

- Iwan's model (Iwan, 1967; Ishihara, 1996): K-0, Q-0, U-0, Y-0;

- logarithmic function model (Puzrin and Shiran, 2000): L-1;

- modified Hujeux model (Aubry et al., 1982): D-0, N-0, S-0;

- multiyield model (Elgamal et al., 2003; Yang et al., 2003): $\mathrm{H}-\mathrm{O}$;

- extended hyperbolic model (Phillips and Hashash, 2009): F-0, H-0, J-0, M-2, T-0;

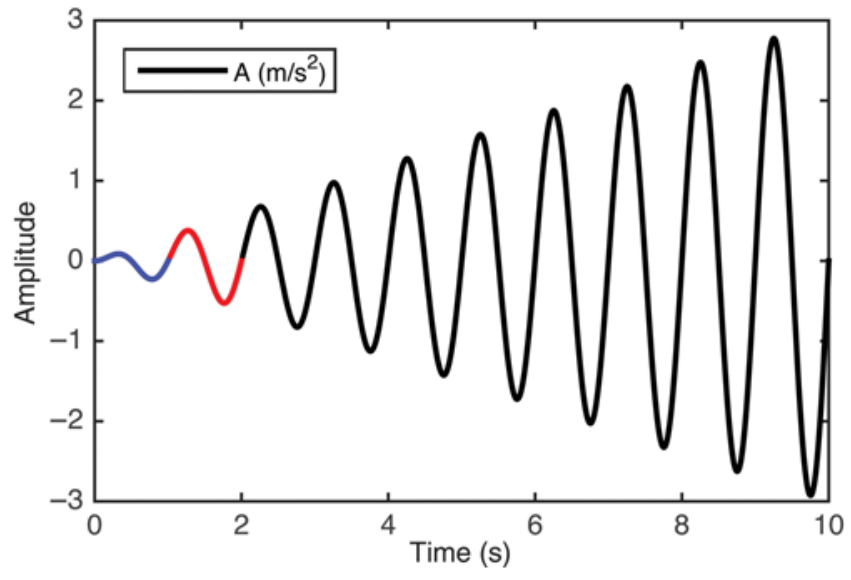

Figure 4. Acceleration time history of the sinusoidal motion with central $1 \mathrm{~s}$ period.

- HSsmall (isotropic hardening elasto-plastic soil model; Schanz et al., 1999): Z-1;

- Pisanò 3D elastic-plastic model (Pisanò and Jeremić, 2014): R-0;

- BWGG: extended Bouc Wen model (Gerolymos and Gazetas, 2005): G-0;

- modified extended hyperbolic model: C-0; and

- Manzari-Dafalias model (Dafalias and Manzari, 2004): W-0.

In order to compare the different constitutive models, stressstrain controlled tests could have been conducted. However, some of the teams were not able to perform them. To overcome this difficulty, we asked the teams to compute nonlinear simulations with their codes on one of the idealized soil profiles (P1) with a sinusoidal input motion of increasing amplitude and with a rigid substratum base (Fig. 4). The frequency of the input motion was low enough to avoid any issues with wave propagation. Moreover, the result of this simulation was recorded at the node above the soil/bedrock interface, having the strength of $65 \mathrm{kPa}$.

The resulting plots are illustrated in Figure 5 for the total length of motion and in Figure 6 for a specific zoom on the first two cycles (blue for the first and red for the second).

The full duration of motion leads to very high-strain levels $(5 \%)$, and the stress-strain curves are highly variable from one computation to another. Even for a similar constitutive model, the curves can differ. For Iwan's model, U-0 and Y-0 results are close to one another while different from those of K-0 and Q-0. The shape of the curves depends also on the use or not of damping control. For instance, teams A-0, B-0, D-0, E-0, J-0, T-0, and F-0 used damping control and all exhibit stress-strain curves with secant modulus degrading with strain.

Some teams (M-0, M-1, M-2, R-0, S-0, W-0) could not follow the prescribed shear strength values mainly because of depth dependency of the shear strength implemented in the code. They used very different values; the comparison of the corresponding stress-strain curve is thus irrelevant. Therefore, we looked at the first two cycles of motion that involve much lower strain (not exceeding 0.5\%): the stress-strain 

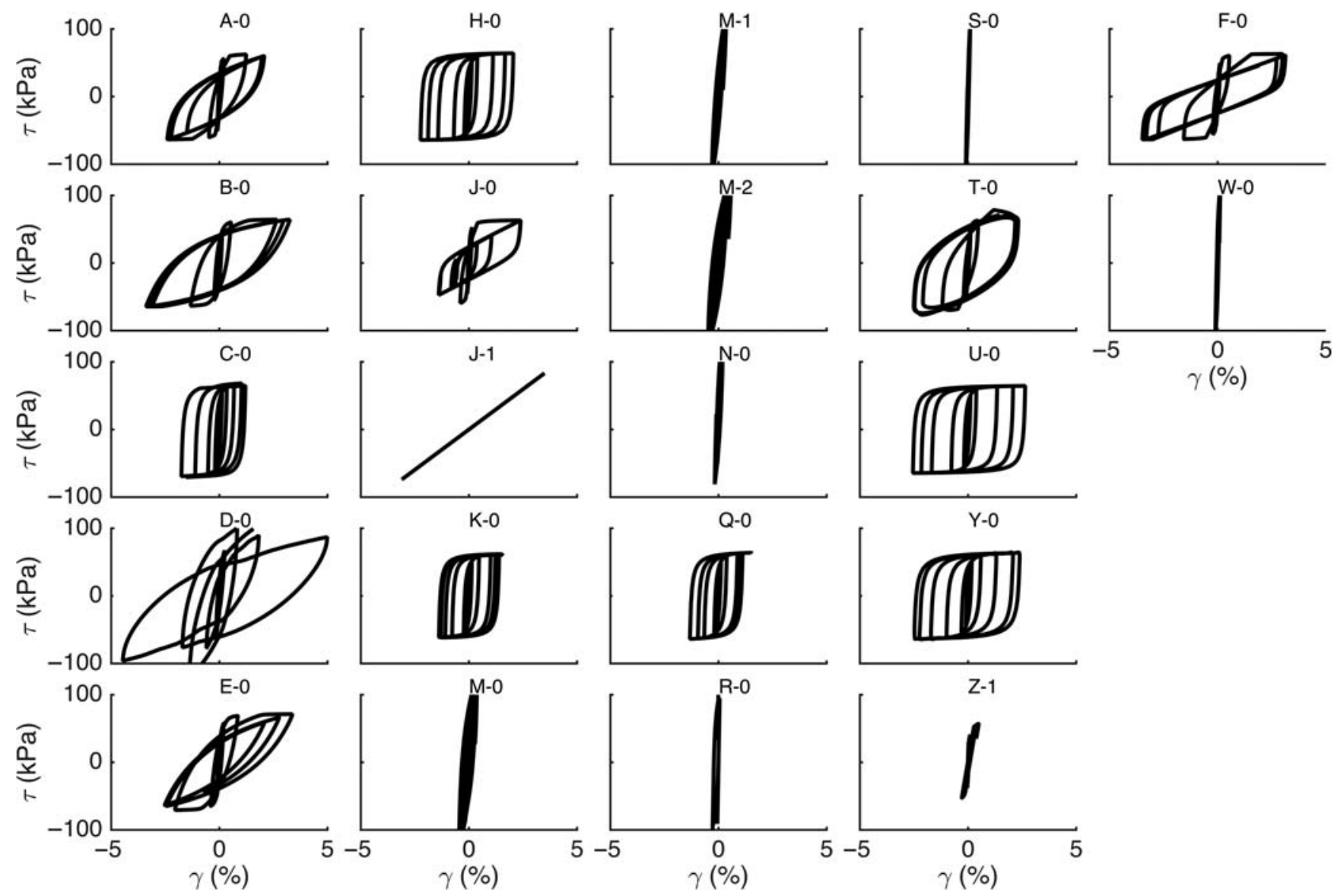

Figure 5. Stress-strain curve for a soil element of shear strength $65 \mathrm{kPa}$ subjected to a sinusoidal input seismic motion of $10 \mathrm{~s}$.

curves are closer to each other, although some indicate larger hysteresis loop (B-0) or lower maximal shear strain (Z-1). This comparison helped to emphasize that hardwired built-in features on some NL codes, based on empirical correlations or geotechnical relations (between the shear strength and the confining pressure, for instance) prevent consideration of fully arbitrary sets of NL parameters.

\section{Code Usage Protocols}

Reference Frequency for Viscoelastic Damping (Maxwell/ Zener Model). Relatively little is known about low-strain intrinsic attenuation in real soils. Its traditional implementation supposes frequency-independent damping values. This is readily achieved using the Kelvin-Voigt model when solving the wave propagation in the frequency domain (Ishihara, 1996). Conversely, the Maxwell/Zener generalized body better describes anelastic material properties in both the time- and frequency-domain solution of wave propagation (Moczo et al., 2004). However, the use of this rheology implies a slight velocity dispersion to fulfill the causality principle. It is therefore necessary to carefully define a reference frequency for the reference velocity value, especially when different numerical methods are compared with one another (Peyrusse et al., 2014). (This reference frequency must not be confused with the frequency bandwidth defini- tion of the quasi-constant $Q$ value used in the frequencyindependent attenuation method mentioned above, it should simply be within this frequency bandwidth.)

A reference frequency was thus defined for each profile, at which common velocity and attenuation values were fixed. As indicated by some authors (Moczo et al., 2004; Liu and Archuleta, 2006), the values of reference frequency used in most cases is close to $1 \mathrm{~Hz}$ (because many 3D computations including shallow and soft material have rather low upperbound maximum frequencies). On the other hand, it is often suggested to select a frequency close to the frequency of interest. In our case, given the definition of the pulse-like motion, we chose a reference frequency of $4 \mathrm{~Hz}$, that is, the central value of the input wavelet.

Definition and Implementation of the Reference Motion. We tested two base conditions at the sediment-substratum interface: (1) an elastic base, and (2) a rigid base. The first condition corresponds to the usual hazard assessment studies, in which the rock ground motion is derived from deterministic or probabilistic analysis, and corresponds to the design motion at the surface of an outcropping rock. The second corresponds to the case in which a recording is obtained at depth within a downhole array, and is used to derive the motion at surface or shallower depths. Depending on the 

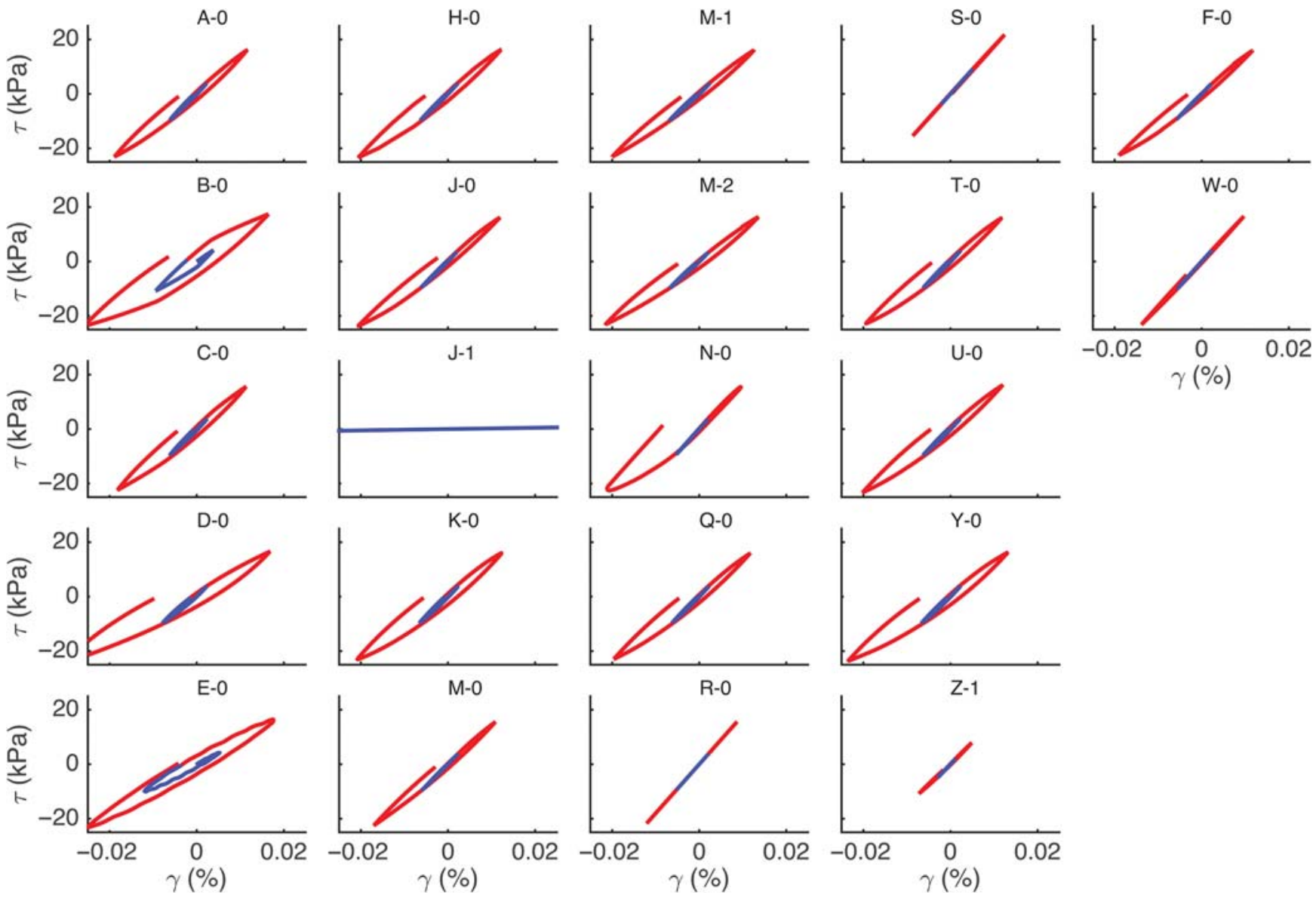

Figure 6. Stress-strain curve for a soil element of shear strength $65 \mathrm{kPa}$ subjected to the first two cycles of a sinusoidal input seismic motion.

communities or points of view, the implementation of input (or reference) motions into algorithms can be quite different, indicating that the terms "input motion" or "reference motion" are not understood in the same way by all the participants. For the seismological community, input motion is often seen as the seismic signal carried by the upgoing incident wave, whereas for the geotechnical community, it is often understood as the motion at a given reference rock site, resulting from the total wavefield (upgoing and downgoing waves). This reference site may be either at the rock surface (it then includes the free-surface effect) or at depth (for instance the downhole sensor of a vertical array, which includes the interferences between the upgoing and downgoing waves; Bonilla et al., 2002).

For the case of a perfectly rigid substratum, reference input motion is the signal imposed at the soil-bedrock interface. This definition was clear among all teams. It was not so clear for the elastic substratum condition, whereby a more precise definition was required, because the greatest differences in the first round of results came from different understandings of the term "input motion" by various teams. The terminology must therefore be clearly stated:

- Outcrop motion: Seismic motion recorded at the surface and corresponding to free-surface conditions in the outcropping rock. For $1 \mathrm{D}$ cases, with vertically propagating plane seismic waves and homogeneous rock, this freesurface effect is simply a frequency-independent factor of 2, with respect to the upgoing wave signal.

- Surface motion: Seismic motion recorded at the free surface of a sedimentary site and subjected to amplification effects.

- Within motion: Seismic motion recorded at depth, usually at a downhole site; in our case, this location corresponds to the interface between sediment and rock substratum (i.e., $z=20,100$, and $50 \mathrm{~m}$, for profiles P1, P2, and $\mathrm{P} 3$, respectively). This motion contains the total wavefield composed of the incident upgoing and reflected downgoing waves.

- Incident motion: Seismic motion that is carried by the incoming waves before they enter the sedimentary cover. In our case, it is the seismic motion carried by the vertically incident plane wave, and it cannot be directly measured.

Considering the confusion among the participants linked with different working traditions in different communities, we decided to use the concepts of outcrop and within input motions to define the reference motion at the downhole sensor, as recommended by Kwok et al. (2008) and Stewart and Kwok (2009). In linear/equivalent linear/NL site response analyses, two cases can be distinguished: 


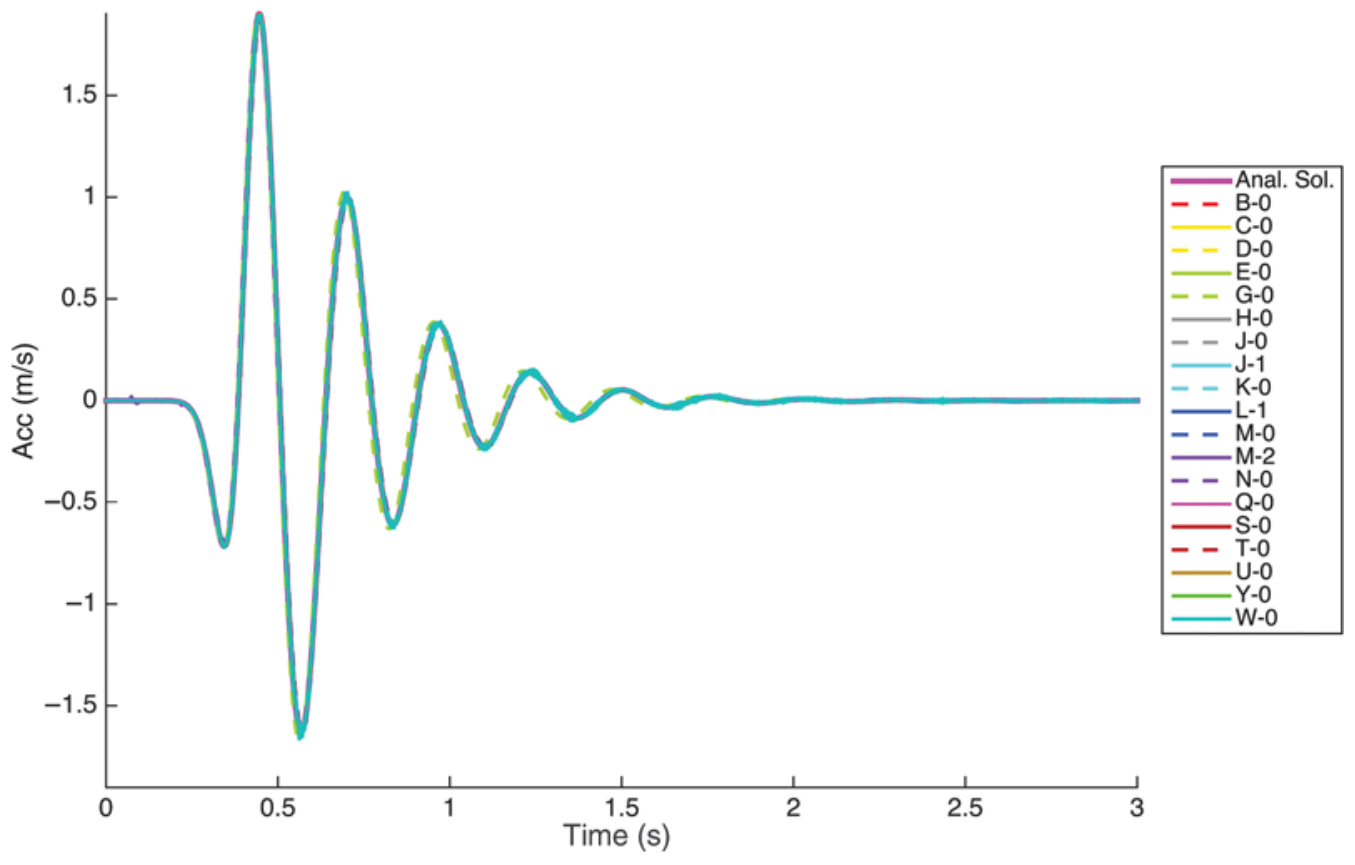

Figure 7. Comparison of the acceleration at the surface of P1 profile, for the pulse-like input motion, for the linear elastic computation and for the elastic substratum case.

1. if the reference motion is an outcrop recording, then one should use an elastic base condition with an upgoing wave carrying a signal equal to exactly half the outcropping motion;

2. if the reference motion is a within motion recorded by a downhole sensor, then one should use a rigid base condition without modifying the input motion.

In order to avoid any ambiguity, we will systematically use the expression reference motion, which should be understood as detailed above for the elastic and rigid base conditions. Furthermore, this reference motion implicitly considers vertically incident plane $S$ waves only. Finally, each team was free to choose the timestep needed to fulfill the stability conditions of the used numerical scheme.

\section{Comparison of Predictions}

\section{Methodology of Comparison}

The participants were asked to compute the acceleration and stress-strain time histories at virtual sensors located at different depths within the soil profile. A total of 10 virtual sensors were selected for each profile, with a depth interval equal to one-tenth of the total soil thickness: every $2 \mathrm{~m}$ for $\mathrm{P} 1$, every $10 \mathrm{~m}$ for $\mathrm{P} 2$, and every $5 \mathrm{~m}$ for P3. Acceleration and stress-strain values should be computed at staggered points: from the very surface for acceleration, and from half the depth interval for stress-strain values.

From the raw results provided by each participant, a comparative analysis was performed on the computed acceleration time histories, transfer function, 5\% pseudoresponse spectra, the depth distribution of peak shear strain and PGA, and the stress-strain plots at different depths. Such comparisons were done for each profile, for each computational case (linear versus NL, elastic versus viscoelastic soil behavior, and rigid versus elastic substratum conditions) and for the different input motions.

For the sake of simplicity and conciseness, the main section of the present article presents results for only the P1 case. The results of $\mathrm{P} 2$ and $\mathrm{P} 3$ profiles are only compared to the results of P1 in terms of variability of the surface motion, but the conclusions are based on the results from all three profiles.

\section{Viscoelastic Computations}

Figure 7 displays the comparison for the P1 profile of the surface acceleration for the pulse-like motion under an elastic substratum condition, for the linear elastic computation for a short window ( $3 \mathrm{~s}$ ) of signal. All results converged toward the analytical solution calculated with the HaskellThomson method (Thomson, 1950; Haskell, 1953), but this was achieved only after the second iteration. There were indeed unexpected and significant discrepancies in amplitude at the end of the first iteration, caused by (1) inconsistent implementation and understanding of the term input motion (clarified as mentioned in the code usage protocols), (2) problems with units, or (3) representations of soil properties. During the first iteration, some phase discrepancies could be also identified, associated either with the assignment of the input motion at different depths some distance below the sediment/rock interface (which caused a constant time delay) or with increasing time delays at the end of the computed cycles that were associated with numerical dispersion. 


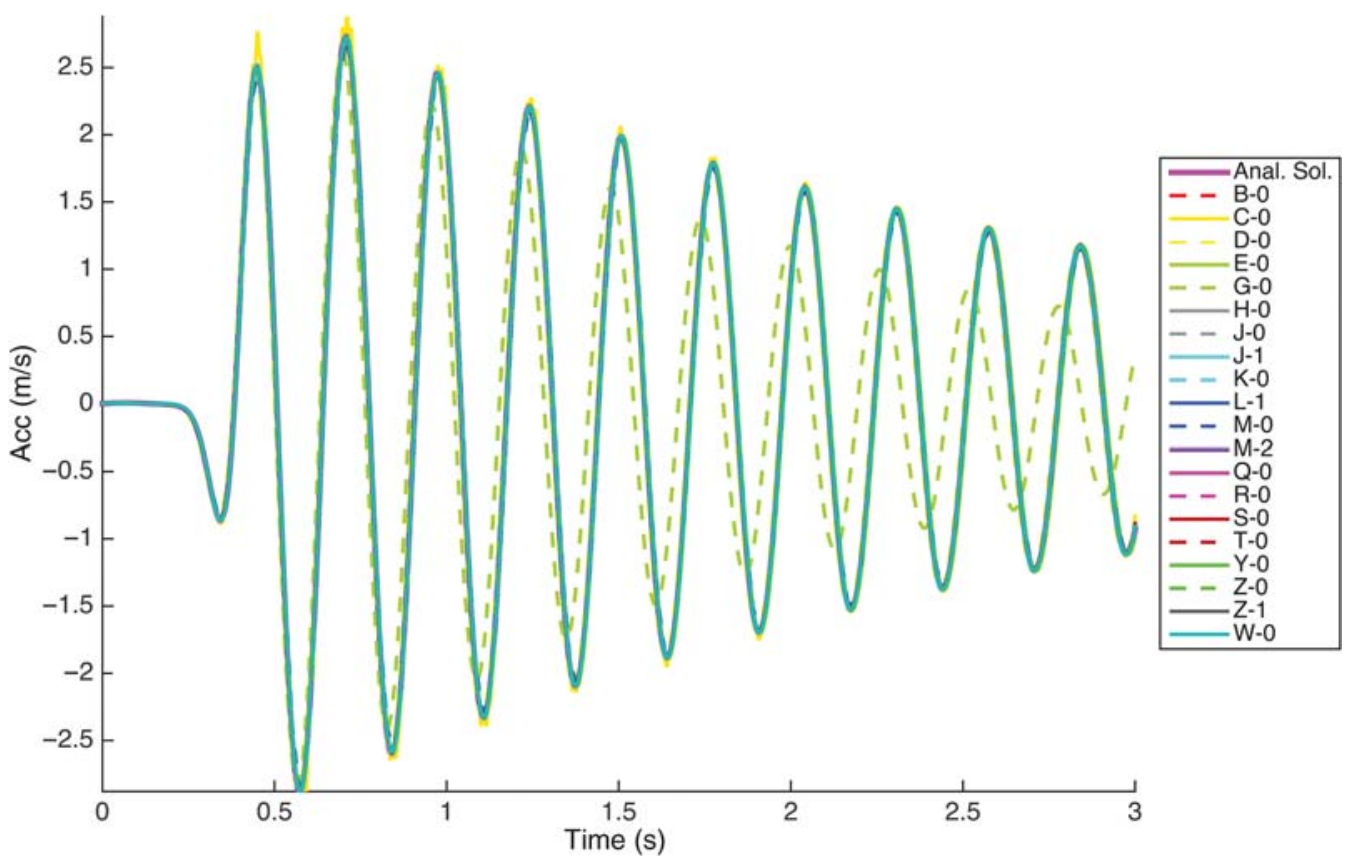

Figure 8. Comparison of the acceleration at the surface of P1 profile, for the pulse-like input motion, for the linear viscoelastic computation, and for the rigid substratum case.

Figure 8 shows the results of viscoelastic computations of the acceleration at the surface of the pulse-like motion with a rigid substratum condition. The convergence was also obtained after the second iteration, with minor corrections (similar to the ones observed for the elastic case) and after having specified the reference frequency to be considered for the implementation of damping. We chose a reference frequency of $4 \mathrm{~Hz}$, which is exactly the central frequency of the pulse-like motion (Fig. 8)

These unexpected issues were corrected after the first iteration to ensure a satisfactory convergence. This should, however, raise our awareness of the possibility of such misunderstandings and resulting errors, when site response computations are asked without clear enough specifications about the definition of the reference motion.

\section{NL Computations}

Once agreement between the model predictions was reached for simple linear cases for which analytical solutions are available, the variability of the results of NL calculations can be fully associated with differences in implementation of NL soil behavior. Each team chose its appropriate timestep to fulfill the stability conditions of their numerical scheme. We acknowledge that this might be another cause for some discrepancies in the results, especially for strongly nonlinear cases, but such numerical issues are also one component of the code-to-code variability that is under investigation in this verification exercise.

Figure 9 compares the Fourier transfer functions (surface over reference bedrock motion) and Figure 10 compares pseudoresponse spectra at the surface for the P1 profile, with a rigid substratum case. The subplots of these two figures illustrate the results for the HF waveform scaled to the lowest $\left(0.5 \mathrm{~m} / \mathrm{s}^{2}\right)$ and largest PGA $\left(5 \mathrm{~m} / \mathrm{s}^{2}\right)$ (Figs. 9a, 10a and 9c, $10 \mathrm{c}$, respectively), and for the LF waveform scaled to the lowest and largest PGA $\left(0.5\right.$ and $5 \mathrm{~m} / \mathrm{s}^{2}$; Figs. $9 \mathrm{~b}, 10 \mathrm{~b}$ and $9 \mathrm{~d}$, $10 \mathrm{~d}$, respectively). The frequency content of the input motion and the scaling of the input motion prove to have a large influence on the NL soil behavior in the numerical simulations, and consequently on the variability of the results.

Although the results from all teams exhibit a very satisfactory similarity (with larger differences than for the viscoelastic case) for the HF waveform scaled to the lowest PGA (Figs. 9a, 10a), differences between the model predictions are much greater for the highest PGA (Figs. 9c, 10c). This observation is more pronounced when looking at the LF input motion. Even for the lowest PGA (Figs. 9b, 10b), the variability increases significantly compared with the $\mathrm{HF}$ input motion, and it becomes very large for the large amplitude LF motion (scaled to $5 \mathrm{~m} / \mathrm{s}^{2}$, Figs. 9d, 10d).

The amount of variability between the results has been quantified through calculation of the standard deviation (in $\log _{10}$ units) for each frequency value and is illustrated in Figure 11. The variability is greater for the LF content input motion scaled to the highest PGA except close to the first frequency peak of the linear transfer function. As expected, strong NL soil behavior during this solicitation shifts the first frequency peak of the transfer function to the low frequencies. The variability of the transfer function is similarly shifted.

Such variability is strongly linked to the peak shear strain reached in the soil column. For the LF input motion scaled to the highest PGA, the threshold shear strain above 

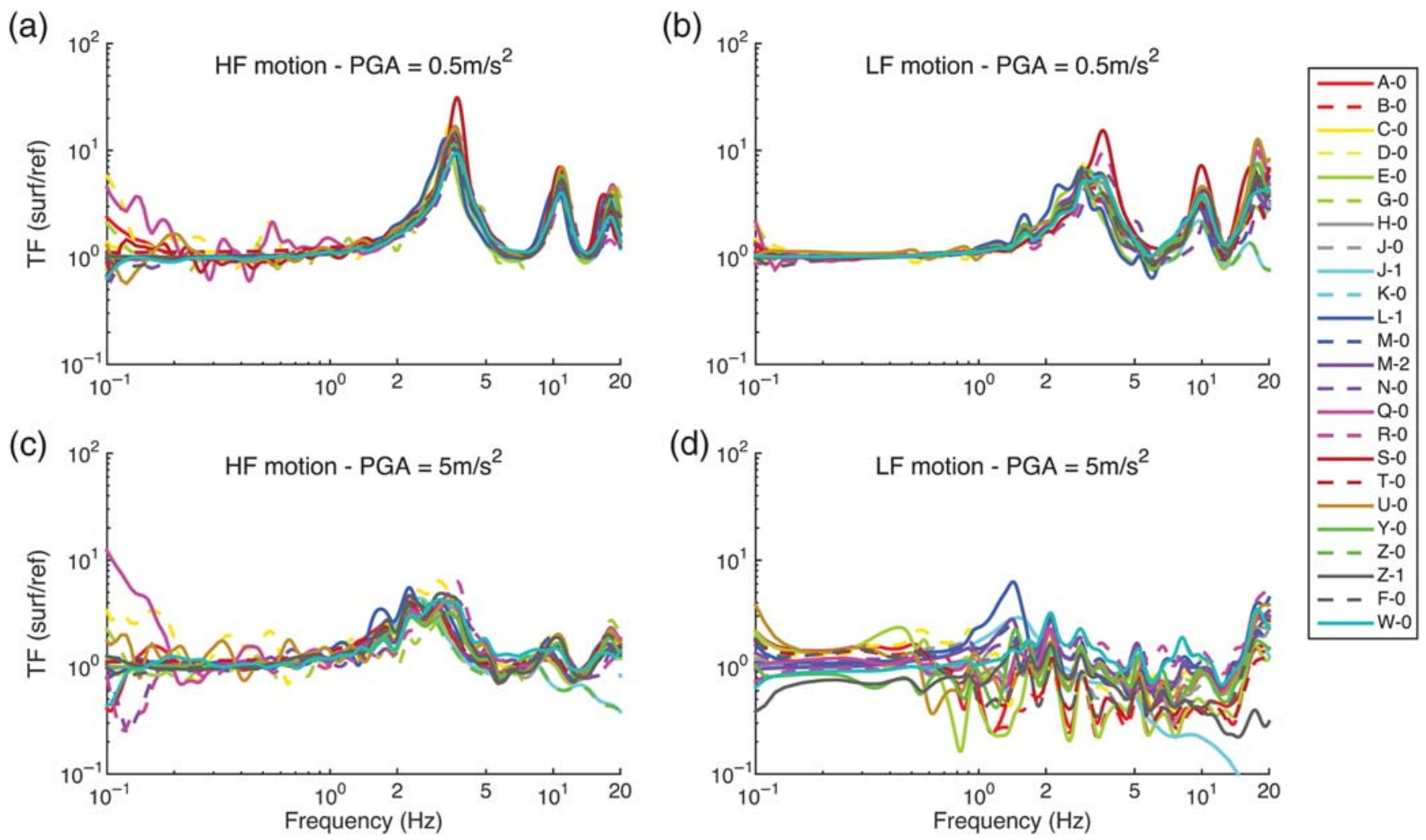

Figure 9. Comparison of the surface to reference Fourier spectra ratio, for the nonlinear (NL) computations using the HF input motion (a) scaled to $0.5 \mathrm{~m} / \mathrm{s}^{2}$ and (c) scaled at $5 \mathrm{~m} / \mathrm{s}^{2}$, and using the LF input motion (b) scaled to $0.5 \mathrm{~m} / \mathrm{s}^{2}$ and (d) scaled at $5 \mathrm{~m} / \mathrm{s}^{2}$.
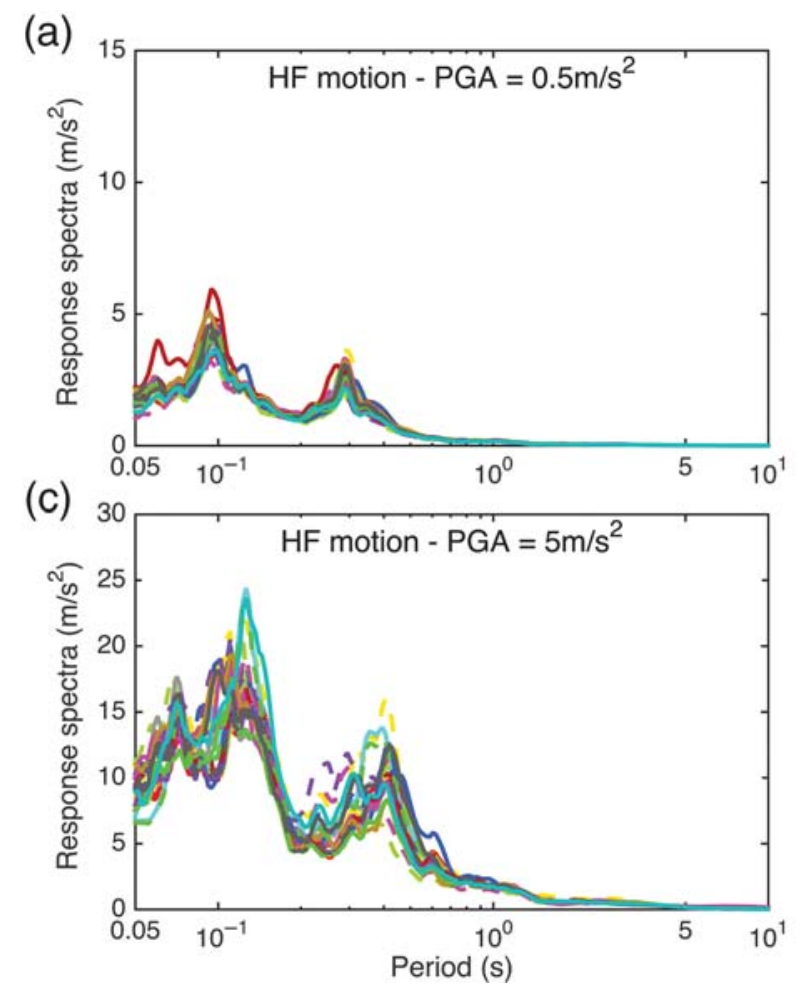

(b)

(d)
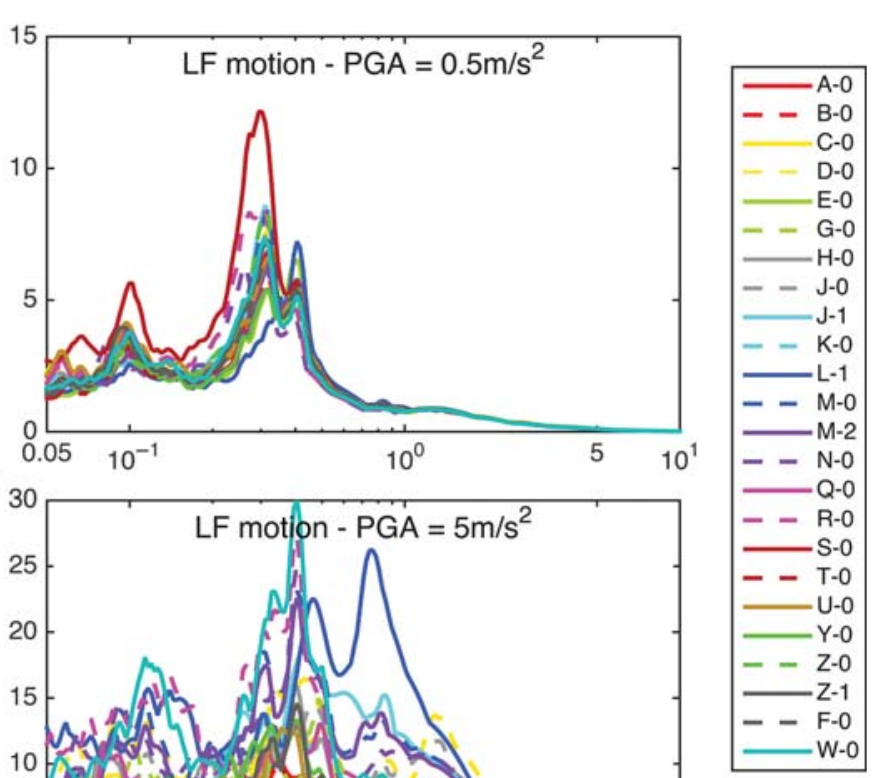

Figure 10. Comparison of the acceleration pseudoresponse spectra at the ground surface, for the NL computations using the HF input motion (a) scaled to $0.5 \mathrm{~m} / \mathrm{s}^{2}$ and (c) scaled at $5 \mathrm{~m} / \mathrm{s}^{2}$, and using the LF input motion (b) scaled to $0.5 \mathrm{~m} / \mathrm{s}^{2}$ and (d) scaled at $5 \mathrm{~m} / \mathrm{s}^{2}$. 

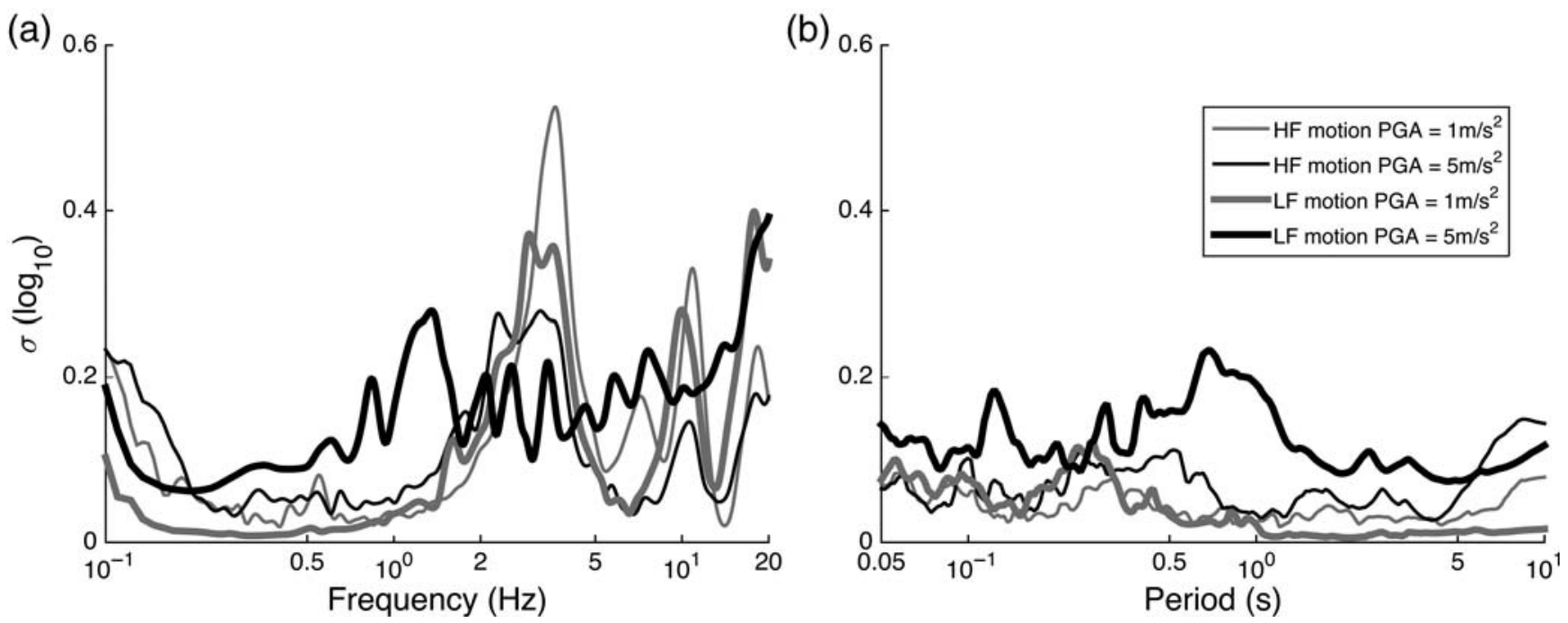

Figure 11. Standard deviation (in log unit) of the (a) transfer function and (b) response spectra (RS) depending on the input motion used.
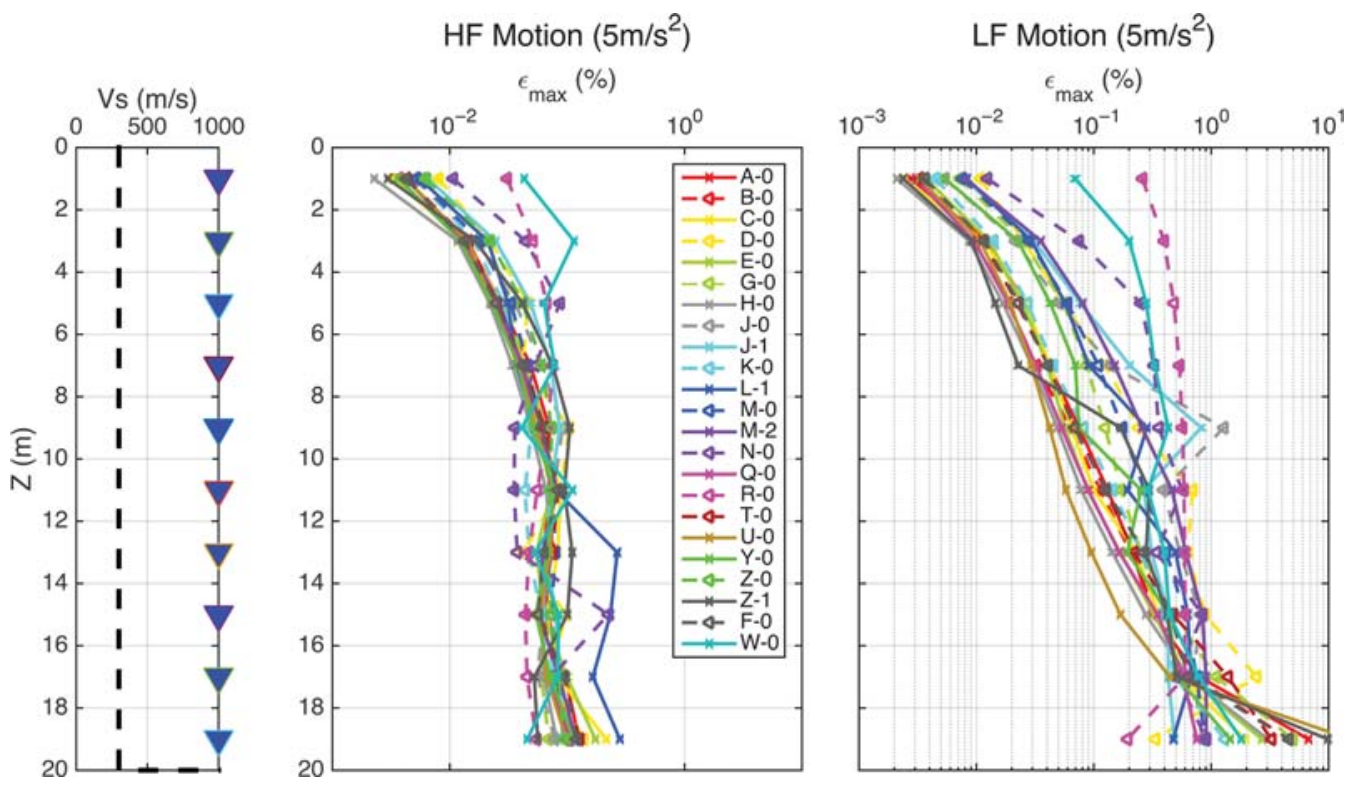

Figure 12. Peak shear-strain profiles reached at each depth by each team for the HF and LF reference motion scaled at the highest PGA level $\left(5 \mathrm{~m} / \mathrm{s}^{2}\right)$, for profile 1 and for rigid substratum conditions.

which the numerical simulations can no longer be considered as reliable (according to their authors), was reached by some codes. Indeed, some teams (L-1 and Z-0) consider a maximal reliable deformation between $1 \%$ and $2 \%$; although others consider their code to work well over a wide range of deformation and are limited by the dynamic soil properties resolution only. For the computations using the HF and LF motions scaled to the highest PGA, we observe that the two equivalent linear methods ( $\mathrm{J}-1$ and Z-0) exhibit a very high deamplification beyond $7 \mathrm{~Hz}$, compared with other simulations, which shows the classical overdamping limitation of that method. For the last two cases (HF and LF accelerograms scaled to $5 \mathrm{~m} / \mathrm{s}^{2}$ ), the peak shear-strain values are illustrated in Figure 12. It was calculated for each code/team couple and all the 10-sensor depths of the $\mathrm{P} 1$ profile. The largest peak strain values, largely exceeding $1 \%$, are reached at the deepest points for the LF input motion, whereas it remains about 10 times smaller $(\max 0.3 \%)$ for the HF motion, despite the identical PGA values on the input motion. Besides, given the shape of the $G / G_{\max }$ and $\xi(\gamma)$ curves, one may notice that the frequency content of the input motion induced variability in the peak shear-strain results which corresponds to an even larger variability in the $G / G_{\max }$ and $\xi(\gamma)$ values. For instance, at $7 \mathrm{~m}$ depth, the peak shear strain for the LF motion is between $0.02 \%$ and $1 \%$, whereas it is between $0.03 \%$ and $0.1 \%$ for the HF motion. This means that $G / G_{\max }$ varies from 0.28 for the 
(a)

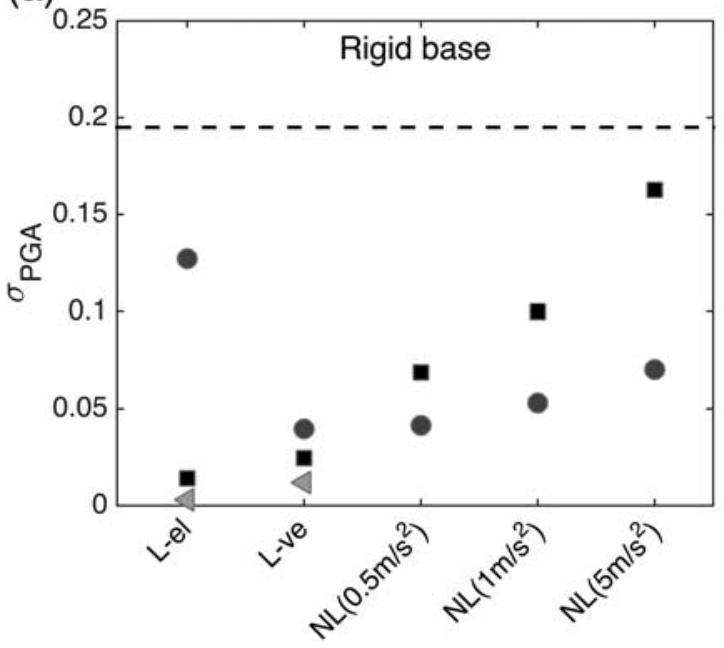

(b)

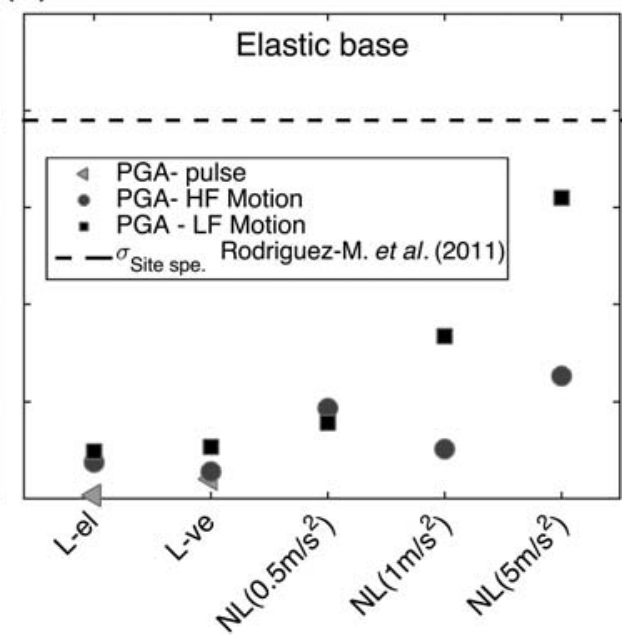

Figure 13. Standard deviation (in $\log _{10}$ unit) of PGA at the surface of the P1 profile, for the five different computational cases: linearelastic; linear-viscoelastic; NL with input motion scaled to the lowest $\left(0.5 \mathrm{~m} / \mathrm{s}^{2}\right)$; medium $\left(1 \mathrm{~m} / \mathrm{s}^{2}\right)$; and highest $\left(5 \mathrm{~m} / \mathrm{s}^{2}\right)$ PGA, for the pulselike, the HF and LF content motions. (a) The results for the rigid substratum case and (b) the elastic substratum.

LF motion to 0.8 for the HF motion. Thus, one may understand that the results will be very sensitive to the details of the constitutive model and to the way that $G / G_{\max }$ and $\xi(\gamma)$ curves are approximated.

Incidentally, one may also notice that for P1, the peak shear strain occurs at the deepest point, close to the sediment/ bedrock interface. Indeed, wave propagation in nonlinear media is the cumulative effect of impedance contrast at the soil-bedrock interface, material strength, and intensity of the input motion. These combined effects make it difficult to analyze these results even when they are numerical and consider simple soil geometry.

\section{Epistemic Uncertainty}

Quantification of the Variability of the Results

We quantified the variability between the simulations by the standard deviations ( $\log _{10}$ units) of several ground-motion intensity parameters, starting with PGA values $\left(\sigma_{\mathrm{PGA}}\right)$, and then considering pseudoresponse spectrum ordinates at different periods $\left[\sigma_{\mathrm{PSA}(\mathrm{T})}\right]$, peak strains $\left(\sigma_{\gamma \max }\right)$, and a few energy related quantities.

The PGA values at the surface are first compared with the empirical variability (i.e., single station, within-event variability $\left.\Phi_{\mathrm{SS}}\right)$. Figure 13 illustrates the evolution of $\sigma_{\mathrm{PGA}}$ for the surface site of P1 for the five different computational cases and the different reference motion and boundary conditions. These are the linear-elastic, linear-viscoelastic, and NL computations with input motions scaled to the lowest $\left(0.5 \mathrm{~m} / \mathrm{s}^{2}\right)$, intermediate $\left(1 \mathrm{~m} / \mathrm{s}^{2}\right)$, and highest $\left(5 \mathrm{~m} / \mathrm{s}^{2}\right)$ PGA. The $\sigma_{\mathrm{PGA}}$ is calculated for the pulse-like, HF, and LF motions. Figure 13a displays the results for the rigid substratum case (reference motion = within motion at sediment-basement interface), whereas Figure 13b stands for the elastic substratum case (reference motion = outcropping rock motion). The most striking features of these plots can be summarized as follows:

(a) the (almost) systematic increase of $\sigma_{\mathrm{PGA}}$ with increasing PGA level, whatever the input signal and the type of boundary conditions;

(b) the (almost) systematically larger values of $\sigma_{\mathrm{PGA}}$ for the LF input motion compared with the HF input motion case (around twice as great for the three PGA values): this corresponds to the higher strains generated by the LF motion. A similar plot as a function of peak strain instead of PGA would exhibit a larger continuity between results of both input waveforms;

(c) the larger $\sigma_{\mathrm{PGA}}$ values for NL computations compared with the linear case (except for the very specific case of linear-elastic response with rigid boundary conditions, discussed later);

(d) the maximum obtained $\sigma_{\mathrm{PGA}}$ value $(0.15)$ remains below the specific single-station, within-event variability $\Phi_{\text {SS,PGA }}$ value for a site with a $V_{S 30}$ equivalent to P1 (Rodriguez-Marek et al., 2011), which is around 0.2. The uncertainties linked with the NL simulations remain below the natural single site response variability (at least for PGA values not exceeding $5 \mathrm{~m} / \mathrm{s}^{2}$ and the very peculiar and simplified input wavefield considered here, consisting of pure vertically incident plane $S$ waves. The latter one however includes the sensitivity to the characteristics of the incident wavefield, which is not accounted for here as only vertically incident plane waves are considered. Nonetheless, the use of PGA as a main metric is not enough. It is helpful to use spectral accelerations at other periods as well.

Our results indicate an exceptionally high $\sigma_{\mathrm{PGA}}$ value for one linear computation, the linear-elastic one with the HF refer- 
(a)

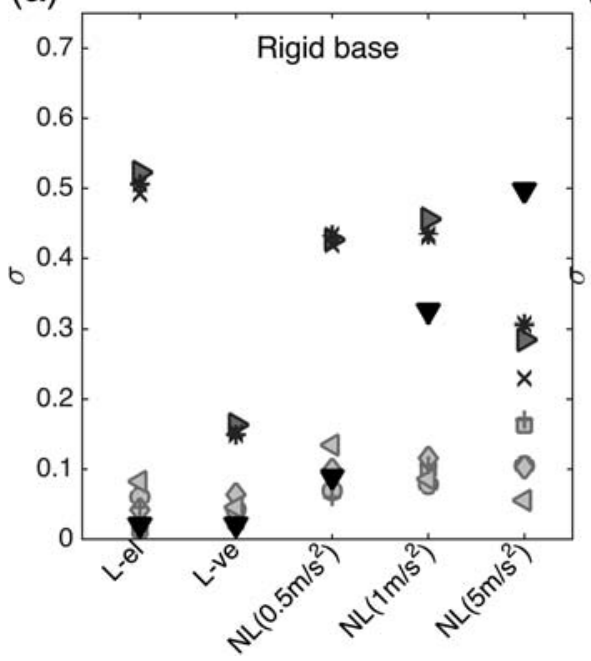

(b)

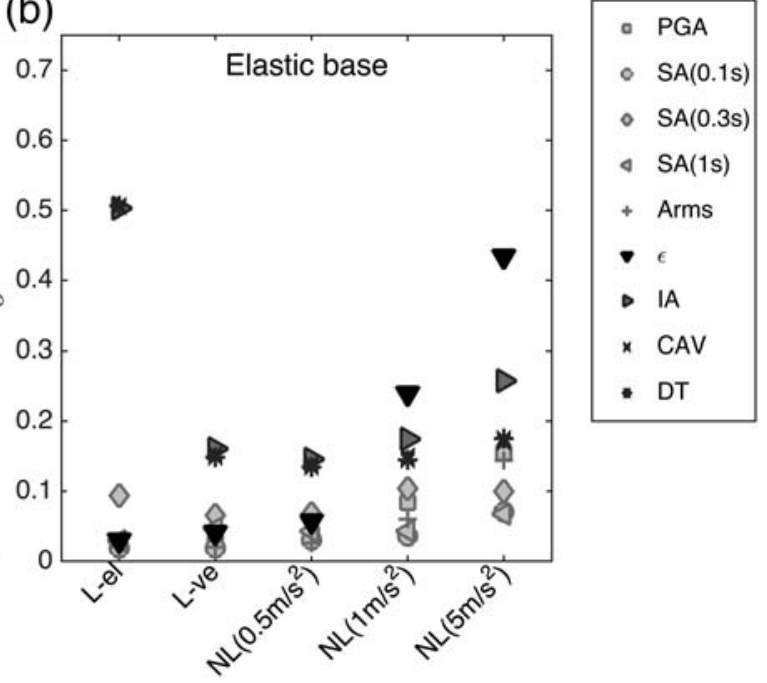

Figure 14. Standard deviation (in log unit) of the different intensity parameters for the P1 profile, for the five different computational cases: linear-elastic, linear-viscoelastic, NL with input motion scaled to the lowest $\left(0.5 \mathrm{~m} / \mathrm{s}^{2}\right)$, medium $\left(1 \mathrm{~m} / \mathrm{s}^{2}\right)$, and highest $\left(5 \mathrm{~m} / \mathrm{s}^{2}\right)$ PGA, for the LF content motion. (a) The results for the rigid substratum case and (b) the elastic substratum.

ence motion and rigid boundary conditions. This computational case is the simplest but also the most demanding for a propagating seismic wave. Considering that no seismic attenuation (damping) is considered for this specific computation (in the material or in the substratum), some codes usually use numerical attenuation to control real motion amplitudes. Thus, the high uncertainty observed here reflects variability in the implementation of the ND for each code/team couple, together with the high sensitivity to the configuration, with a nonzero Fourier content of the reference motion at depth, at a frequency in which destructive interferences between upgoing and downgoing waves should result in a null motion.

We then explored the variability of various seismic intensity measures: (1) the response spectra (RS) at the surface (SA) at three different periods $(0.1,1$, and $3 \mathrm{~s})$, (2) the peak shear strain at the bottom of the sediment layer $(\varepsilon)$, (3) the cumulative absolute velocity (CAV), (4) the Arias intensity $\left(I_{\mathrm{A}}\right)$, (5) the root mean square acceleration (Arms), and (6) the 5\%-95\% Trifunac-Brady duration (DT). The tendencies are quite similar for the HF and LF motions, but are sensitive to the sediment/substratum limit condition (elastic versus rigid). Considering that $\sigma_{\mathrm{PGA}}$ is greater for the $\mathrm{LF}$ motion, we choose that motion to illustrate the results in Figure 14. For the rigid substratum case (left subplot), three groups of intensity parameters are identified. The first group is composed of duration-dependent intensity parameters, that is, CAV, $I_{\mathrm{A}}$, and DT, which exhibit the largest $\sigma$ values. The second group is composed of acceleration parameters (PGA, $\mathrm{SA}(T)$, Arms) and characterized by a lower $\sigma$, especially for the long period [SA $(T=1 \mathrm{~s})$ ]. The third group consists only of the peak strain, with generally intermediate $\sigma$ values, which exhibit the largest variability from one case to another. These three groups can also be distinguished in the elastic substratum case (right subplot), for which the largest caseto-case variability is also observed for the peak strain, exhib- iting the highest $\sigma$ for the highest PGA values. The durationdependent parameters of the first group are less variable under elastic boundary conditions especially at low to intermediate PGA levels and in the linear domain: rigid base conditions are very demanding for low-damping materials, which maps much more on duration than on peak values.

The other profiles provided similar results as to the variability of predictions. As an example, Figure 15 compares the PGA variability, for the LF motion and a rigid substratum case, for the three profiles. The trends are similar for the three profiles: similar $\sigma$ values and the same tendency to increase with PGA. These results also stand for the elastic substratum case, as well as the fact that the variability $\sigma$ is lower for the HF motion for the three profiles, by about a factor of 2 compared with the LF motion.

Origins of the Variability: Can It be Reduced?

Definition of Groups and Subgroups. We considered four $a$ priori ways to group the results according to some characteristics of the numerical codes: (G1) implemented attenuation method, (G2) numerical scheme, (G3) constitutive model, (G4) shape of the hysteretic curve according to (1) the ability to represent the actual shear strength value (here at the bottom of P1), and (2) the use or not of Masing rules for the loading/unloading path (damping control or not). Each group is further sorted into several subgroups as follows.

Case G1 concerns the implementation of linear intrinsic damping, as defined in the first part of this article. It is subdivided into three subgroups: (1) G1a: frequency-independent attenuation (A-0, E-0, F-0, J-0, J-1, K-0, M-0, Q-0, and Z-0), (2) G1b: Rayleigh damping (B-0, G-0, H-0, L-1, M-1, R-0, S-0, T-0, W-0, Y-0, and Z-1), and (3) G1c: low-strain hysteretic damping (C-0, N-0, D-0 and, R-0). 


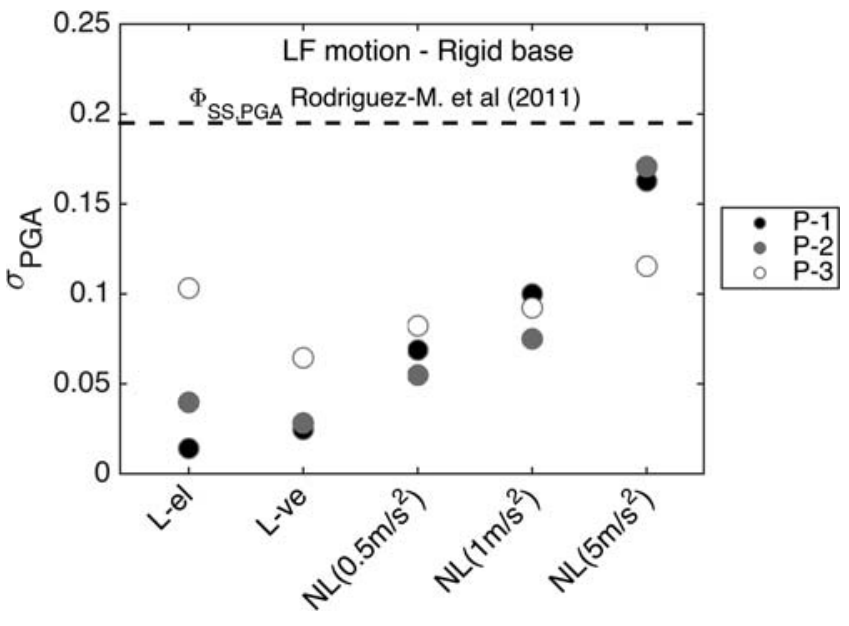

Figure 15. Standard deviation (in log unit) of PGA for profiles 1 , 2 , and 3 , for the five different computational cases (linearelastic, linear-viscoelastic, NL with input motion scaled to the lowest).

Case G2 is based on the numerical discretization scheme, which is subdivided into two subgroups: (1) G2a: finite element (B-0, D-0, H-0, L-1, M-0, N-0, Q-0, R-0, S-0, T-0, U-0, W-0, Y-0, and Z-1) and (2) G2b: finite difference (A-0, C-0, E-0, F-0, G-0, J-0, K-0, L-2, M-2). A third subgroup could be considered $(\mathrm{G} 2 \mathrm{c})$ consisting of equivalent linear codes working in the frequency domain ( $\mathrm{J}-1$ and $\mathrm{Z}-0)$.

Case G3 is based on the constitutive model. To ensure sufficient teams within each group, we split the code/team couple into four subgroups according to the main constitutive model used: (1) G3a: Iai's model (B-0, E-0, Q-0), (2) G3b: Iwan's model (K-0, L-1, U-0, Y-0), (3) G3c: Philips and Hashash's model (F-0, J-0, L-2, M-2, T-0), and (4) G3d: all other models.

Case G4 is based on the shape of the hysteresis loop according to (1) the shear strength used by each code/team couple and (2) the use of Masing rules or not for the loading/ unloading path.

In the canonical models initially designed by the organizing team, the soil shear strength profile was assumed to be constant with the depth in each soil layer, and had prescribed modulus reduction and damping curves. However, in most real situations, the shear strength should increase with depth. Even though these profiles were considered as idealized and simply intended to perform these verification tests, some teams felt very uncomfortable with this unrealistic assumption and decided to change the shear strength profile, by introducing a more realistic increase in shear strength with depth, having nevertheless the imposed strength values at the center of each layer. Consequently, the actual NL soil parameters considered by each team were not identical, which is certainly responsible for part of the final variability observed, especially for large ground motions, for which the actual strain and damping are more sensitive to the shear strength than to the shear velocity, particularly at, or close to, major interfaces. For this reason, we further sorted each code/team couple into two subgroups, by analyzing the stress-strain plots for the LF motion and the highest PGA at the bottom of P1 (illustrated in Fig. 16). We chose this computational case because it is the most challenging in terms of maximal shear strain reached in the soil column and therefore can highlight the differences between the computations. We found the following subgroups: (1) shear strength is equal to $65 \mathrm{kPa}$, as stated by the organizing team (A-0, B-0, C-0, E-0, F-0, G-0, H-0, K-0, Q-0, U-0, T-0, Y-0), and (2) all others that exceeded this value (D-0, J-0, J-1, L-1, N-0, M-0, M-1, M-2, R-0, S-0, W-0, Z-0, Z-1).

In addition, we also consider the damping control implementation (or in other words the use or not of the Masing loading/unloading rules). It has a major influence on the hysteresis curves and hence on the NL soil behavior, also illustrated in Figure 16. It is split into two subgroups: (1) damping control is used, that is, the Masing rules are not applied (A-0, B-0, E-0, F-0, J-0, M-2, and T-0), and (2) no damping control is used (all other teams).

Combining these two last parameters we end up for G4 with three subgroups as follows: (1) G4-a: Specified shear strength and use of damping control (A-0, B-0, E-0, F-0, T-0), (2) G4-b: Specified shear strength and no use of damping control (C-0, G-0, H-0, K-0, Q-0, U-0, Y-0), and (3) G4-c: Different shear strength (D-0, J-0, J-1, L-1, N-0, M-0, M-1, M-2, R-0, S-0, W-0, Z-0, Z-1).

Variability within the Subgroups. Considering the level of code-to-code variability, and its increase with PGA or strain level, a major issue regarding NL computations is whether such variability, that is, the uncertainty in the predicted motion, is intrinsic to these kinds of calculations, or can be reduced, and in the latter case, how? We thus looked at the variability within each subgroup of the four main groupings, in order to identify those which are associated with a significantly reduced scatter.

The standard deviations ( $\sigma_{\log }$, calculated in $\log _{10}$ units) of three parameters describing the computed surface accelerations and the strain levels at the bottom of P1 were used as metrics to validate the ability of a given grouping item to reduce the scatter of results. These parameters are the surface PGA and the acceleration RS at periods 0.3 and $0.09 \mathrm{~s}$ (corresponding to P1's first and second resonance frequencies, respectively). For each, the variability was measured within each subgroup of the four groups. If the groupings are physically relevant, the within-subgroup variability should be significantly reduced.

Figure 17 shows the standard deviation values for each subgroup in each group (G1-G4) relative to the general standard deviation (all unsorted code/team couples) illustrated by the dashed gray line. The standard deviation of the PGA, RS at two periods, and maximal deformation are calculated on the results for the profile $\mathrm{P} 1$, with the rigid substratum case and using the LF input motion scaled to the highest PGA (i.e., the motion that induces the strongest deformation in the soil column). 


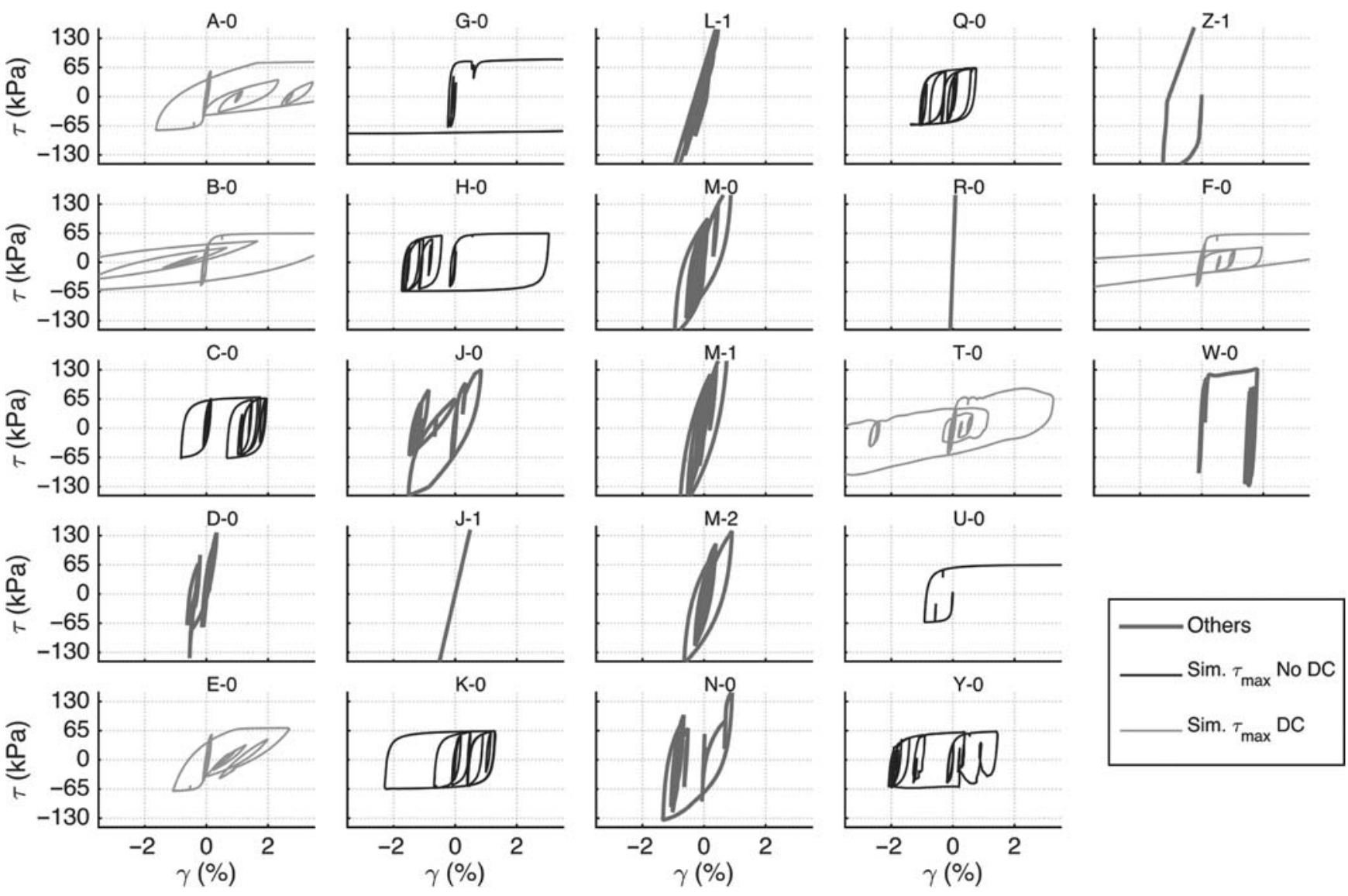

Figure 16. Stress-strain curves at the bottom of the P1 profile for the rigid substratum case subjected to the LF motion (scaled to the highest PGA $\left.\left[5 \mathrm{~m} / \mathrm{s}^{2}\right]\right)$. The thicker curves are for code/team couples that exceed the specified shear strength of $65 \mathrm{kPa}$, whereas the thin curves represent the code/team couples that use $65 \mathrm{kPa}$. The lighter curves are for codes using damping control and the darker curves the others.
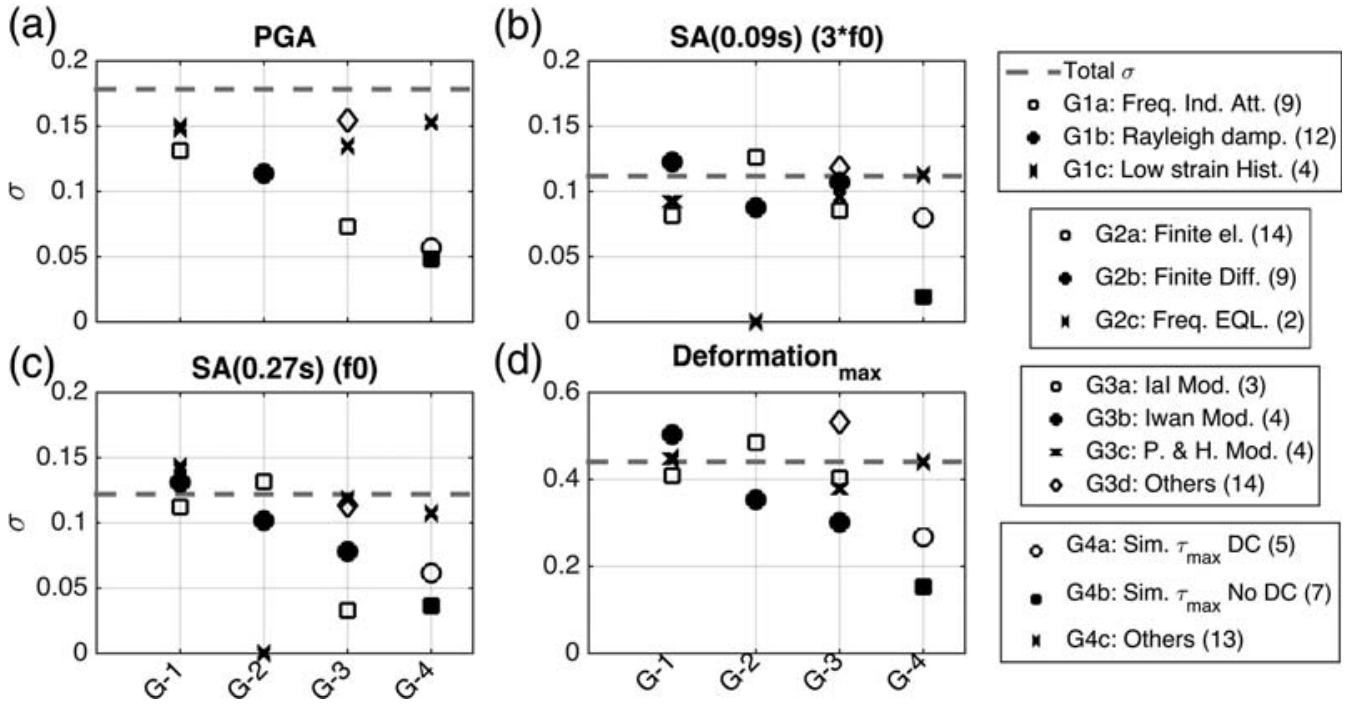

- G3a: lal Mod. (3)

- G3b: Iwan Mod. (4)

- G3c: P. \& H. Mod. (4)

- G3d: Others (14)

- G4a: Sim. $\tau_{\max } \mathrm{DC}(5)$
- G4b: Sim. $\tau_{\max }$ No DC (7)
- G4c: Others (13)

Figure 17. Standard deviation values $\left(\sigma_{\log }\right.$, in $\log _{10}$ units) of four parameters for the NL computation using the LF content input motion scaled to the highest PGA: (a) RS at $0.27 \mathrm{~s}$, (b) RS at $0.09 \mathrm{~s}$, (c) all three at the surface of P1, and (d) the maximal shear deformation at the bottom of P1. The standard deviations are given for each of the four groupings: depending on their low-strain attenuation implementation (G1), their numerical scheme (G-2), their constitutive models (G-3), and their values of shear strength at the bottom of P1 and use of damping control or not (G-5). The dashed-gray line illustrates the standard deviation for all code/team couples. 
(a)

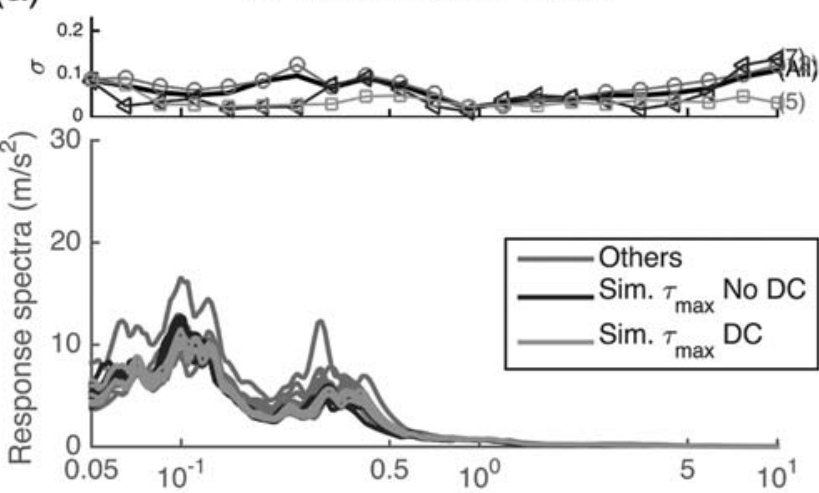

(c) $\quad H F$ motion $-P G A=5 m / s^{2}$
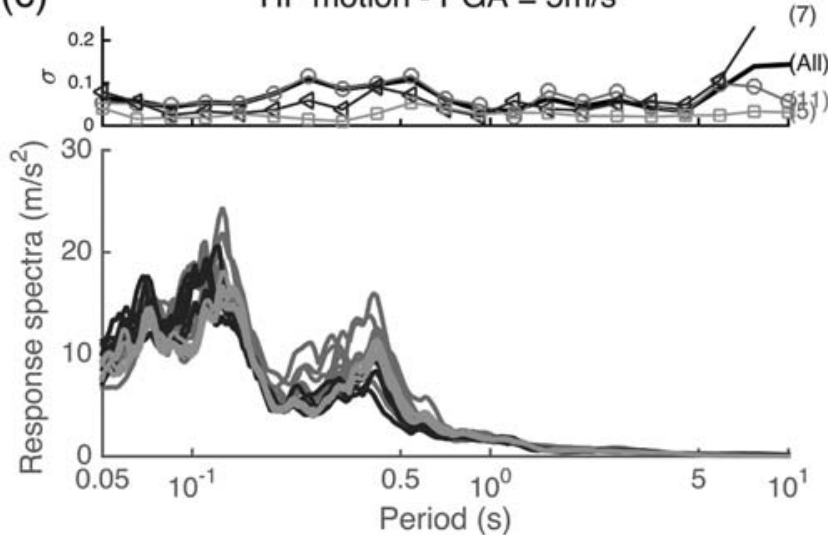

(b) LF motion $-P G A=1 \mathrm{~m} / \mathrm{s}^{2}$
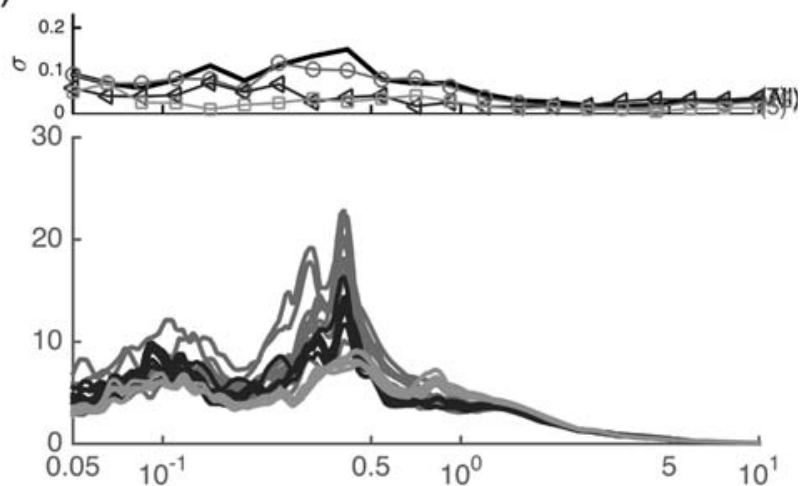

(d)

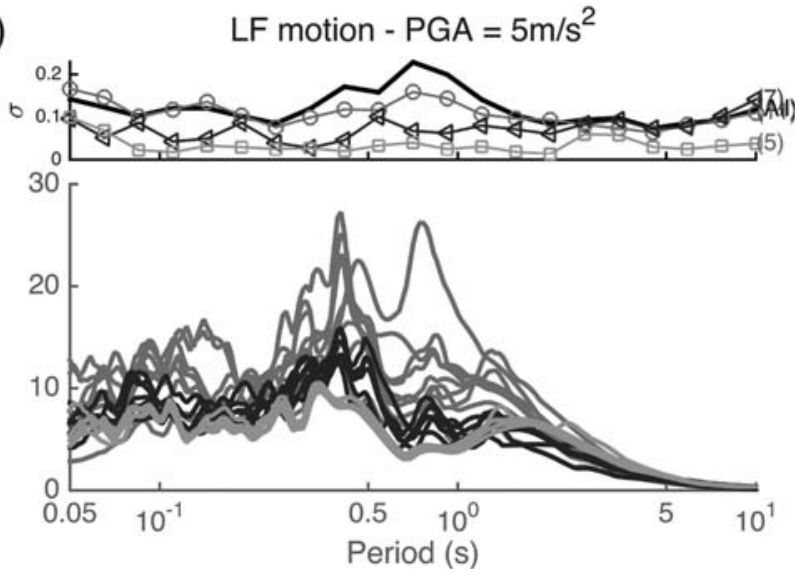

Figure 18. Comparison of the pseudoacceleration RS at the ground surface of $\mathrm{P} 1$ with rigid substratum condition, for the NL computation using for (a) and (c) graphs the HF input motion and for (b) and (d) graphs the LF input motion and with for the (a) and (b) graphs the middle input motion PGA and the (c) and (d) graphs the highest input motion PGA. The RS were sorted according to three groups: group 1 is composed of the code/team couples using similar $\tau_{\max }$ and damping control constitutive model, group 2 use similar $\tau_{\max }$ and no damping control, and group 3 are the other code/team couples. The standard deviation for each subgroup is compared with the standard deviation using all results in the upper graphs, the figures indicate the number of simulations that are in each group.

G1 and G2 (i.e., low-strain attenuation and numerical scheme implementation, respectively) do not exhibit much lower $\sigma_{\log }$ values compared with the general $\sigma_{\log }$, except for the lowest PGA input motion. Conversely, G3 to G4 (i.e., constitutive model, shear strength, and damping control groups) do show reduced $\sigma_{\log }$ relative to the general $\sigma_{\log }$, with G4 demonstrating the strongest reductions (by at least a factor of 2).

We can therefore conclude that (1) the shear strength is a key parameter for NL computations, and (2) the constitutive model has a large influence, however, (3) the use (or not) of Masing rules appears to have an even greater influence for strong input motion.

Figure 18 compares the pseudoacceleration RS at the surface of the P1 profile with a rigid substratum condition subjected to LF and HF input motions scaled at the medium $\left(1 \mathrm{~m} / \mathrm{s}^{2}\right)$ and the highest $\left(5 \mathrm{~m} / \mathrm{s}^{2}\right)$ PGA levels. The RS are sorted according to the G4 subgrouping, and the associated $\sigma_{\log }$ is represented by the thin lines on top of each subplot (the numbers on the right side indicate the number of code/team pairs in each subgroup). G4 enables a clear distinction of the RS; particularly for the most demanding LF input motion. The $\sigma_{\log }$ values from the two subgroups with identical $\tau_{\max }(\mathrm{G} 4 \mathrm{a}$ and G4b) are considerably reduced below $2 \mathrm{~s}$, compared with the rest of the computations (G4c). This period bandwidth is relative to the PGA of this LF input motion. Similarly, for the $\mathrm{HF}$ input motion, the $\sigma$ is reduced below $1 \mathrm{~s}$.

Besides, the RS computed for the strongest input motions (HF and LF) at the surface of groups G4a and G4b are significantly different from to another which shows the large impact of using damping control or not. The RS computed with damping control are more damped at intermediate frequencies (period between [0.2-0.7] and [0.2-1] s for the HF and LF motions, respectively) and less attenuated at low frequencies (periods greater than 0.7 and $1 \mathrm{~s}$ for the HF and LF motions, respectively).

\section{Conclusions}

In the PRENOLIN's verification phase, the linear computation involving a simple pulse-like (Ricker) input motion proved to be very useful in understanding and eliminating some of the discrepancies between the different numerical codes that were compared. It was found that code-to-code differences can be attributed to three different sources: (1) minor 
mistakes in input parameter implementation or output units, (2) different understanding of the expression input motion within different communities, and (3) different intrinsic attenuation and numerical integration implementations. This benchmark showed that any nonlinear code should be tested with simple linear cases before going into nonlinear computations to ensure the proper implementation of the elastic soil parameters.

Most of the codes tested in this verification benchmark were designed mainly for NL computations. Therefore, although the codes should well reproduce the soil behavior at low strains, their actual performances are mainly tested for their soil behavior predictions during strong shaking in real cases.

The results obtained so far indicate a code-to-code variability, which increases with the shear-strain level (which in turn depends on both the PGA level, stiffness of the soil, and the frequency content of the reference input motion). For example, for the LF input motion, at low-PGA values $\left(0.5 \mathrm{~m} / \mathrm{s}^{2}\right)$ at the base of the soil column, the standard deviation is 0.065 in logarithmic units, whereas for a PGA of $5 \mathrm{~m} / \mathrm{s}^{2}$, the standard deviation is 0.17 . We also found that, whatever the soil profiles used (among the three soil profiles considered), the overall code-to-code variability in the worst case (with strain levels exceeding 1\%) remained lower than the random variability of ground-motion prediction equation (GMPE) single-station $\sigma$-values for PGA. Nevertheless, an important conclusion is that given the scatter in the nonlinear results, a realistic analysis should use more than one code to perform a site response computation.

The effect of different NL soil model implementations was explored in this study and our main observations indicate that the epistemic uncertainty (i.e., the code-to-code variability) can be significantly reduced by describing more precisely some specific input parameters, especially the soil shear strength profile, which is found to be a key specification in addition to the degradation curves. In addition, when damping control is used, the variability of the stress-strain curves was found to be large. This point deserves further research in future studies. All these features and conclusions need to be checked against actual data to provide support for defining best practice for modeling nonlinearities in soft soils. In that aim, vertical arrays having multiple downhole sensors constitute indeed the best available in situ instrumentation to go forward with this kind of study. The benchmark undoubtedly benefits a lot from the various expertise fields of the participants ranging from geotechnical earthquake engineering to engineering seismology.

\section{Data and Resources}

Time histories used in this study were collected from the KiK-net website www.kik.bosai.go.jp and http://www.kik. bosai.go.jp/kik/ (last accessed November 2011) and from the University of Iceland, Engineering Research Institute, Applied Mechanics Laboratory, Reykjavik, Iceland.
Some codes used in this work have the following URL links: ASTER, http://www.code-aster.org (last accessed October 2015); EPISPEC1D, http://efispec.free.fr (last accessed October 2015); Real ESSI simulator, http://sokocalo.engr. ucdavis.edu/ jeremic/Real_ESSI_Simulator/ (last accessed October 2015); OpenSees, http://opensees.berkeley.edu/ (last accessed October 2015); DEEPSOIL, http://deepsoil.cee. illinois.edu/ (last accessed October 2015); SeismoSoil, http://asimaki.caltech.edu/resources/index.html\#software (last accessed October 2015). The unpublished manuscript by J. Shi and D. Asimaki (2016), "From stiffness to strength: Formulation and validation of a hybrid hyperbolic nonlinear soil model for site response analyses," was submitted to Bulletin of the Seismological Society of America.

\section{Acknowledgments}

Such an exercise was made possible by the interest and funding of the French and Italian nuclear industry under the project SeIsmic Ground-Motion Assessment (SIGMA). It was made successful thanks to the dedicated and proactive participation of many teams from all over the world: a large number of teams reacted very positively to our invitation to take part in this (risky) benchmarking exercise, among them the developers of a wide variety of internationally used constitutive laws and/or codes. Such a broad participation witnesses the actual need for such a carefully controlled comparison, and also brought an invaluable enrichment to the project, which undoubtedly benefitted greatly from the deep expertise of the participants. PREdiction of NOn-LINear soil behavior (PRENOLIN) is part of two larger projects: SINAPS@, supported from French funding managed by the National Research Agency under the program Future Investments (SINAPS@ reference number ANR-11RSNR-0022), and SIGMA, funded by a consortium of nuclear operators (EDF, CEA, AREVA, ENL). The authors want to thank Associate Editor Eric Chael and the two anonymous reviewers for their constructive comments.

\section{References}

Aki, K., and P. G. Richards (2002). Quantitative Seismology, University Science Books, Sausalito, California, 704 pp.

Aubry, D., and A. Modaressi (1996). GEFDYN, Manuel Scientifique, Éc. Cent. Paris LMSS-Mat.

Aubry, D., J. C. Hujeux, F. Lassoudiere, and Y. Meimon (1982). A double memory model with multiple mechanisms for cyclic soil behaviour, Proc. of the Int. Symp. Num. Mod. Geomech, 3-13.

Bardet, J. P., K. Ichii, and C. H. Lin (2000). EERA: A Computer Program for Equivalent-Linear Earthquake Site Response Analyses of Layered Soil Deposits, University of Southern California, Department of Civil Engineering, Los Angeles, California.

Benz, T. (2006). Small strain stiffness of soils and its consequences, Ph.D. Thesis, IGS Universiät Stuttgart, Stuttgart, Germany.

Benz, T., P. A. Vermeer, and R. Schwab (2009). A small-strain overlay model, Int. J. Numer. Anal. Methods Geomech. 33, 25-44.

Beresnev, I. A., K.-L. Wen, and Y. T. Yeh (1995). Nonlinear soil amplification: Its corroboration in Taiwan, Bull. Seismol. Soc. Am. 85, 456-515.

Biot, M. A. (1956). Theory of propagation of elastic waves in a fluidsaturated porous solid. I. Low-frequency range, J. Acoust. Soc. Am. 28, 168-178, doi: 10.1121/1.1908239.

Blanch, J. O., J. O. Robertsson, and W. W. Symes (1995). Modeling of a constant $Q$ : Methodology and algorithm for an efficient and optimally inexpensive viscoelastic technique, Geophysics 60, 176-184.

Bonilla, L. F., R. J. Archuleta, and D. Lavallée (2005). Hysteretic and dilatant behavior of cohesionless soils and their effects on nonlinear site response: Field data observations and modeling, Bull. Seismol. Soc. Am. 95, 2373-2395. 
Bonilla, L. F., J. H. Steidl, J. Gariel, and R. J. Archuleta (2002). Borehole response studies at the Garner Valley downhole array southern California, Bull. Seismol. Soc. Am. 92, 3165-3279.

Boore, D. M., and J. J. Bommer (2005). Processing of strong-motion accelerograms: Needs, options and consequences, Soil Dynam. Earthq. Eng. 25, 93-115.

Chin, B.-H., and K. Aki (1991). Simultaneous study of the source, path, and site effects on strong ground motion during the 1989 Loma Prieta earthquake: A preliminary result on pervasive nonlinear site effects, Bull. Seismol. Soc. Am. 81, 1859-1884.

Cundall, P. (2006). A simple hysteretic damping formulation for dynamic continuum simulations, Proc. of the 4th International FLAC Symposium on Numerical Modeling in Geomechanics, Itasca Consulting Group, Minneapolis, Minnesota.

Dafalias, Y. F., and M. T. Manzari (2004). Simple plasticity sand model accounting for fabric change effects, J. Eng. Mech. 130, 622-634.

Darendeli, M. B. (2001). Development of a new family of normalized modulus reduction and material damping curves, Ph.D. Dissertation, University of Texas, Austin, Texas.

Day, S. M., and C. R. Bradley (2001). Memory-efficient simulation of anelastic wave propagation, Bull. Seismol. Soc. Am. 91, 520-531.

Day, S. M., and J. B. Minster (1984). Numerical simulation of attenuated wavefields using a Padé approximant method, Geophys. J. Int. 78, 105-118.

Derras, B., P.-Y. Bard, F. Cotton, and A. Bekkouche (2012). Adapting the neural network approach to PGA prediction: An example based on the KiK-net data, Bull. Seismol. Soc. Am. 102, 1446-1461.

Elgamal, A., Z. Yang, E. Parra, and A. Ragheb (2003). Modeling of cyclic mobility in saturated cohesionless soils, Int. J. Plast. 19, 883-905, doi: 10.1016/S0749-6419(02)00010-4.

Field, E., P. A. Johnson, I. A. Beresnev, and Y. Zeng (1997). Nonlinear ground-motion amplification by sediments during the 1994 Northridge earthquake, Nature 390, 599-602.

Foerster, E., C. Gélis, F. De Martin, and L.-F. Bonilla (2015). Numerical Study of $1 D / 2 D$ Wave Propagation in the Mygnodian Basin, EUROSEISTEST, Northern Greece, 9ème Colloq. AFPS.

Gerolymos, N., and G. Gazetas (2005). Constitutive model for 1-D cyclic soil behaviour applied to seismic analysis of layered deposits, Soil Found. 45, 147-159.

Gerolymos, N., and G. Gazetas (2006). Winkler model for lateral response of rigid caisson foundations in linear soil, Soil Dynam. Earthq. Eng. 26, 347-361.

Graves, R. W., and S. M. Day (2003). Stability and accuracy analysis of coarse-grain viscoelastic simulations, Bull. Seismol. Soc. Am. 93, 283-300.

Hashash, Y. M. A., D. R. Groholski, C. A. Phillips, D. Park, and M. Musgrove (2012). DEEPSOIL 5.1. User Manual and Tutorial 107, The University of Illinois, Urbana, Illinois.

Haskell, N. H. (1953). The dispersion of surface waves in multilayered media, Bull. Seismol. Soc. Am. 43, 17-34.

Iai, S., and O. Ozutsumi (2005). Yield and cyclic behaviour of a strain space multiple mechanism model for granular materials, Int. J. Numer. Anal. Methods Geomech. 29, 417-442, doi: 10.1002/nag.420.

Iai, S., Y. Matsunaga, and T. Kameoka (1990). Strain space plasticity model for cyclic mobility, No. 4, Port and Harbour Research Institute.

Iai, S., Y. Matsunaga, and T. Kameoka (1992). Strain space plasticity model for cyclic mobility, Soil Found. 32, 1-15, doi: 10.3208/sandf1972.32.2_1.

Iai, S., T. Morita, T. Kameoka, Y. Matsungaya, and K. Abiko (1995). Response of a dense sand deposit during 1993 Kushiro-Oki earthquake, Soil Found. 35, 115-131.

Iai, S., T. Tobita, O. Ozutsumi, and K. Ueda (2011). Dilatancy of granular materials in a strain space multiple mechanism model, Int. J. Numer. Anal. Methods Geomech. 35, 360-392, doi: 10.1002/nag.899.

Ishibashi, I., and X. Zhang (1993). Unified dynamic shear moduli and damping ratio of sand and clay, Soil Found. 33, 182-191.

Ishihara, K. (1996). Soil Behaviour in Earthquake Geotechnics, Clarendon Press, Oxford, United Kingdom.
ITASCA (2011). FLAC 7.0: User Manual, Licence Number 213-039-012718973, Sapienza-Univ Rome Earth Sci. Dep.

Iwan, W. D. (1967). On a class of models for the yielding behavior of continuous and composite systems, J. Appl. Mech. 34, 612-617.

Johnston, D. H., M. N. Toksoz, and A. Timur (1979). Attenuation of seismic waves in dry and saturated rocks: II. Mechanisms, Geophysics 44, 691-711, doi: 10.1190/1.1440970.

Kontoe, S. (2006). Development of time integration schemes and advanced boundary conditions for dynamic geotechnical analysis, Ph.D. Thesis, Imperial College London (University of London), London, England.

Kwok, A. O., J. P. Stewart, and Y. M. Hashash (2008). Nonlinear groundresponse analysis of Turkey Flat shallow stiff-soil site to strong ground motion, Bull. Seismol. Soc. Am. 98, 331-343.

Leurer, K. C. (1997). Attenuation in fine-grained marine sediments: Extension of the Biot-Stoll model by the "effective grain model" (EGM), Geophysics 62, 1465-1479, doi: 10.1190/1.1444250.

Li, W., and D. Assimaki (2010). Site-and motion-dependent parametric uncertainty of site-response analyses in earthquake simulations, Bull. Seismol. Soc. Am. 100, 954-968.

Liu, P., and R. J. Archuleta (2006). Efficient modeling of $Q$ for 3D numerical simulation of wave propagation, Bull. Seismol. Soc. Am. 96, 13521358, doi: 10.1785/0120050173.

Matasović, N., and G. A. Ordóñez (2010). D-MOD2000: A computer program for seismic response analysis of horizontally layered soil deposits, earthfill dams, and solid waste landfills, in User's Manual, GeoMotions, LLC, Lacey, Washington, D.C.

Matasovic, N., and M. Vucetic (1993). Analysis of Seismic Records Obtained on November 24, 1987 at the Wildlife Liquefaction Array, University of California, Los Angeles.

Mercerat, E. D., and N. Glinsky (2015). A nodal discontinuous Galerkin method for non-linear soil dynamics, 6th Int. Conf. Earthq. Geotech. Eng., Christchurch, New Zealand, 1-4 November 2015.

Moczo, P., J. Kristek, and M. Gális (2004). Simulation of the planar free surface with near-surface lateral discontinuities in the finite-difference modeling of seismic motion, Bull. Seismol. Soc. Am. 94, 760-768.

Modaressi, H., and E. Foerster (2000). CyberQuake. User's Manual, BRGM Fr, Orléans, France.

Olsen, K., S. Day, and C. Bradley (2003). Estimation of $Q$ for long-period (>2 sec) waves in the Los Angeles basin, Bull. Seismol. Soc. Am. 93, 627-638.

Peyrusse, F., N. Glinsky, C. Gélis, and S. Lanteri (2014). A high-order discontinuous Galerkin method for viscoelastic wave propagation, in Spectral and High Order Methods for Partial Differential EquationsICOSAHOM 2012, Springer, Dordrecht, The Netherlands, 361-371.

Phillips, C., and Y. M. A. Hashash (2009). Damping formulation for nonlinear 1D site response analyses, Soil Dynam. Earthq. Eng. 29, 1143-1158, doi: 10.1016/j.soildyn.2009.01.004.

Pisanò, F., and B. Jeremić (2014). Simulating stiffness degradation and damping in soils via a simple visco-elastic-plastic model, Soil Dynam. Earthq. Eng. 63, 98-109.

Potts, D. M., and L. Zdravkovic (1999). Finite Element Analysis in Geotechnical Engineering: Theory, Imperial College of Science, Technology and Medicine, Thomas Telford Publishing, Thomas Telford Ltd, London, United Kingdom, ISBN 0-7277-2783-4.

Puzrin, A. M., and A. Shiran (2000). Effects of the constitutive relationship on seismic response of soils. Part I. Constitutive modeling of cyclic behavior of soils, Soil Dynam. Earthq. Eng. 19, 305-318, doi: 10.1016/S0267-7261(00)00027-0.

Régnier, J., H. Cadet, L. Bonilla, E. Bertand, and J. E. Semblat (2013). Assessing nonlinear behavior of soil in seismic site response: Statistical analysis on KiK-net strong motion data, Bull. Seismol. Soc. Am. 103, 1750-1770.

Rodriguez-Marek, A., G. A. Mantalva, F. Cotton, and F. Bonilla (2011). Analysis of single-station standard deviation using the KiK-net data, Bull. Seismol. Soc. Am. 101, 1242-1258.

Sandikkaya, M. A., S. Akkar, and P.-Y. Bard (2013). A nonlinear siteamplification model for the next Pan-European ground-motion prediction equations, Bull. Seismol. Soc. Am. 103, 19-32. 
Santisi d'Avila, M. P., and J.-F. Semblat (2014). Nonlinear seismic response for the 2011 Tohoku earthquake: Borehole records versus one-directional three-component propagation models, Geophys. J. Int. 197, 566-580.

Santisi d'Avila, M. P., L. Lenti, and J.-F. Semblat (2012). Modelling strong seismic ground motion: Three-dimensional loading path versus wavefield polarization, Geophys. J. Int. 190, 1607-1624.

Santisi d'Avila, M. P., J.-F. Semblat, and L. Lenti (2013). Strong ground motion in the 2011 Tohoku earthquake: A one-directional threecomponent modeling, Bull. Seismol. Soc. Am. 103, 1394-1410.

Schanz, T., P. A. Vermeer, and P. G. Bonnier (1999). The hardening soil model: Formulation and verification, in Beyond 2000 in Computational Geotechnics, Balkema, Rotterdam, The Netherlands, 281-296.

Schnabel, P. B., J. Lysmer, and H. B. Seed (1972). SHAKE?: A Computer Program for Earthquake Response Analysis of Horizontally Layered Sites (Report), Earthquake Engineering Research Center, Berkeley, California.

Seed, H., and I. M. Idriss (1969). Influence of soil conditions on ground motions during earthquakes, J. Soil Mech. Found Div. Amer. Soc. Civ. Eng. 95, 99-138.

Semblat, J. F. (1997). Rheological interpretation of Rayleigh damping, $J$. Sound Vib. 206, 741-744, doi: 10.1006/jsvi.1997.1067.

Stewart, J., and A. Kwok (2009). Nonlinear seismic ground response analysis: Protocols and verification against array data, PEER Annu. Meet. San Franc.-Present., 84 pp.

Taborda, D. M., L. Zdravkovic, L. Kontoe, and D. M. Potts (2010). Alternative formulations for cyclic nonlinear models: Parametric study and comparative analyses, in Numerical Methods Geotechnical Engineering (NUMGE), T. Benz and S. Nordal (Editors), CRC Press, Boca Raton, Florida, 423-428.

Thomson, W. T. (1950). Transmission of elastic waves through a stratified solid, J. Appl. Phys. 21, 89-93.

Tropeano, G., A. Chiaradonna, A. d'Onofrio, and F. Silvestri (2016). An innovative computer code for 1D seismic response analysis including shear strength of soils, Géotechnique 66, 95-105, doi: 10.1680/jgeot. SIP.15.P.017.

Vucetic, M., and R. Dobry (1991). Effect of soil plasticity on cyclic response, J. Geotech. Eng. 117.

Yang, Z., A. Elgamal, and E. Parra (2003). Computational model for cyclic mobility and associated shear deformation, J. Geotech. Geoenvir. Eng. 129, 1119-1127.

Yu, G., J. G. Anderson, and R. A. J. Siddharthan (1993). On the characteristics of nonlinear soil response, Bull. Seismol. Soc. Am. 83, 218-244.

Zeghal, M., A.-W. Elgamal, H. T. Tang, and T. C. Srepp (1995). Lotung downhole array. II: Evaluation of soil nonlinear properties, J. Geotech. Eng. 121, 363-378.

\section{CEREMA}

DTer Méditerranée

56 Bd Stalingrad

06300 Nice

France

Julie.regnier@cerema.fr

(J.R., E.B., N.G., M.M., E.D.)

IFSTTAR

14-20 Boulevard Newton-Champs-sur-Marne

77447 Marne-la-Vallée, CEDEX 2

France

(L.-F.B.)
CEA, DEN

13108 St Paul lez Durance

France

(F.H.)

DPRI

Gokasho, Uji

Kyoto 611-0011, Japan

(H.K., S.I.)

EDF-DPI-CEIDRE, TEGG

905 av du Camp Menthe

13097 Aix-en-Provence, CEDEX 2

France

(D.S.)

Department of Civil and Environmental Engineering

University of Washington

132 I More Hall

Seattle, Washington 98195-2700

(P.A., L.C., A.G., S.K.)

Sapienza, University of Rome

Via Eudossiana, 18

00184 Roma, Italy

(A.A., L.V.)

California Institute of Technology

1200 East California Boulevard

Pasadena, California 91125

(D.A., J.S.)

Department of Civil, Chemical, Environmental and Materials Engineering University of Bologna

Via Terracini 28

40131 Bologna, Italy

(D.B.)

Department of Civil, Architectural and Environmental Engineering University of Napoli Federico II

via Claudio 21

80125 Naples, Italy

(A.C., F.S.)

BRGM (French Geological Survey)

Direction of Risks and Prevention

3 Avenue Claude Guillemin

45100 Orléans

France

(F.D.)

Politecnico di Torino

Corso Duca degli Abruzzi 24

10129 Torino, Italy

(M.E., S.F.)

University of California, San Diego

Department of Structural Engineering

La Jolla, California 92093-0085

(A.E.) 
Politecnico of Bari

Via Amendola 126

70126 Bari, Italy

(G.F., A.d.L.)

CEA, DEN/DM2S/SEMT/EMSI and SEISM Institute Paris-Saclay 91191 Gif-sur-Yvette, Cedex

France

(E.F.)

National Technical University of Athens (NTUA)

Faculty of Civil Engineering, Geotechnical Department

Iroon Polytechniou 9

Zografou 157 80, Greece

(E.G., G.G.)

IRSN

31 Avenue de la Division Leclerc

92260 Fontenay-aux-Roses

France

(C.G.)

Fugro Sial

Esentepe mah. Yazarlar sok. No. 16

34394 Gayrettepe, Şişli-İstanbul, Turkey

(A.G.)

Kleinfelder, Inc.

550 West C Street, Suite 1200

San Diego, California 92101

(J.R.G.)

University of Illinois at Urbana-Champaign

2230c Newmark Lab

205 N Mathews, M/C 250

Urbana, Illinois 61801

(J.H., Y.H., M.M.)

CEED

University of California

Davis, California 95616

(B.J.)

Imperial College

South Kensington Campus

London SW7 2AZ, UK

(S.K.)

Faculty of Mathematics, Physics and Informatics

Comenius University in Bratislava

Mlynská dolina F1

84248 Bratislava, Slovakia

(J.K., P.M., A.R.)
Sapienza University of Rome

Via A. Gramsci 53

00197 Rome, Italy

(G.L., S.S.)

CentraleSupélec

Paris-Saclay University

MSS-Mat CNRS UMR 8579, Grande Voie des Vignes

Châtenay-Malabry 92290

France

(F.L.-C., S.M.-N.)

Department of Civil Engineering

University of British Columbia

Vancouver, British Columbia

Canada V6T 1Z4

(G.M., M.T.)

Départment Analyses en Mécanique Avancée

EDF Lab Paris-Saclay

7 Boulevard Gaspard Monge

91120 Palaiseau

France

(A.N.-F.)

University of Chieti-Pescara

Viale Pindaro 42

65129 Pescara, Italy

(A.P.)

Geo-Engineering Section/Offshore Engineering Section

Faculty of Civil Engineering and Geoscience

Delft University of Technology

Stevinweg 1

2628 CN Delft, The Netherlands

(F.P.)

Université de Nice Sophia Antipolis, Nice

Campus Valrose

28 avenue Valrose

06108 Nice, CEDEX 2

France

(M.P.S.)

Department of Civil, Environmental Engineering and Architecture University of Cagliari

Piazza d'Armi

09123 Cagliari, Italy

(G.T.)

Shimizu Corporation

No. 16-1, Kyobashi 2-chome, Chuo-ku

Tokyo 104-8370, Japan

(K.W.)

Manuscript received 20 October 2015;

Published Online 22 September 2016;

Corrected Online 4 October 2016 